\title{
Microbial Association with Genus Actinomyces in Primary and Secondary Endodontic Lesions, Review
}

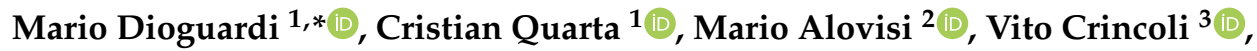 \\ Riccardo Aiuto $\left.{ }^{4}{ }^{(}\right)$, Rolando Crippa ${ }^{5}$, Francesca Angiero ${ }^{6}$, Enrica Laneve ${ }^{1}$, Diego Sovereto ${ }^{1}$, \\ Alfredo De Lillo ${ }^{1}$, Giuseppe Troiano ${ }^{1}$ (D) and Lorenzo Lo Muzio ${ }^{1}$ (D) \\ 1 Department of Clinical and Experimental Medicine, University of Foggia, Via Rovelli 50, 71122 Foggia, Italy; \\ cristian_quarta.549474@unifg.it (C.Q.); enrica.laneve@unifg.it (E.L.); diego_sovereto.546709@unifg.it (D.S.); \\ alfredo.delillo@unifg.it (A.D.L.); giuseppe.troiano@unifg.it (G.T.); lorenzo.lomuzio@unifg.it (L.L.M.) \\ Department of Surgical Sciences, Dental School, University of Turin, 10127 Turin, Italy; mario.alovisi@unito.it \\ 3 Department of Basic Medical Sciences, Neurosciences and Sensory Organs, Division of Complex Operating \\ Unit of Dentistry, “Aldo Moro” University of Bari, Piazza G. Cesare 11, 70124 Bari, Italy; \\ vito.crincoli@uniba.it \\ 4 Department of Biomedical, Surgical, and Dental Science, University of Milan, 20122 Milan, Italy; \\ Riccardo.Aiuto@unimi.it \\ 5 Department of Oral Pathology, Italian Stomatological Institute, 20122 Milan, Italy; \\ rolandocrippamd@gmail.com \\ 6 Department of Medical Sciences and Diagnostic Integrated, S. Martino Hospital, University of Genova, \\ 16132 Genova, Italy; f.angiero@gmail.com \\ * Correspondence: mario.dioguardi@unifg.it
}

Received: 21 June 2020; Accepted: 21 July 2020; Published: 22 July 2020

check for updates

\begin{abstract}
The main reason for root canal treatment failure is the persistence of microorganisms after therapy, or the recontamination of the root canal system due to an inadequate seal. In the mouth, Actinomyces spp. constitute a significant part of the normal flora, which is indicative of their ability to adhere to oral tissue and resist cleansing mechanisms, such as salivary flow. This review, performed according to the Preferred Reporting Items for Systematic Reviews and Meta-Analysis (PRISMA), aims to clarify the prevalence of microbial genera that are associated with the genus Actinomyces in primary and secondary endodontic infections (primary outcome), and to identify the most prevalent species of the Actinomyces genus in endodontic lesions (secondary outcome). A total of 11 studies were included in the qualitative and quantitative analysis, and a total of 331 samples were analyzed. Bacteria of the genus Actinomyces were found in 58 samples, and 46 bacterial genera were detected in association with bacteria of the genus Actinomyces. Bacteria of the genus Streptococcus and Propionibacterium were those most frequently associated with Actinomyces in the endodontic lesions considered, and Actinomyces israelii was the most frequently involved species.
\end{abstract}

Keywords: Actinomyces; apical periodontitis; endodontic failure; primary endodontic infection; secondary endodontic infection

\section{Introduction}

The main reason for the failure of root canal treatment is the persistence of microorganisms after therapy, or the subsequent contamination of the root system due to an inadequate seal (Nair, P.N., 2004). In endodontic failures, the presence of microorganisms has been reported in $35 \%$ to $100 \%$ of cases, with Cheung et al. reporting the presence of cultivable microorganisms in $66 \%$ of samples from teeth with endodontic failures $[1,2]$. 
Modern endodontic treatment aims to remove microorganisms from the infected root canal before filling. In some circumstances, bacteria survive endodontic treatment and can cause endodontic failure [3].

The main cause of apical periodontitis is the invasion of the endodontic space by infectious agents that cause infection [4]. Although chemical and physical factors are recognized to play a role in causing apical inflammation in the scientific literature, microorganisms are considered to be fundamental in the onset and the chronicization of apical periodontal diseases [5].

Microorganisms can reach the dental pulp through the dentinal tubules, leading to carious lesions, infiltrated restorations, dental trauma and lateral periodontal lesions with apical involvement (through lateral channels or the apical foramen) [6].

Torabinejad et al. have shown that contamination (Staphylococcus epidermidis and Proteus vulgaris) from the occlusal side can reach the periapical area in less than 6 weeks, in channels blocked with gutta-percha and sealer [7]. If the temporary filling is broken, the structure of the tooth is fractured before the definitive filling, or the filling is inadequate, bacteria can access the periapical tissue and cause infections; bacteria gain access to the pulp when the thickness of the dentine between the edge of the carious lesion and the pulp is $0.2 \mathrm{~mm}[8]$.

Dental pulp contaminated by the presence of microorganisms is related to the onset of apical periodontal disease. The shaping and simultaneous cleansing of the infected endodontic lesion reduces the bacterial load, and the subsequent root canal filling followed by restoration creates an apical and coronal seal that increases the probability of a favorable prognosis after treatment. Endodontic failure is determined, in some cases, by the persistence of microorganisms within the canals, which determines the presence of a persistent or secondary intraradicular infection $[9,10]$.

Microorganisms can give rise to persistent infections when they survive canal cleansing and disinfection procedures, and if bacteria infect the endodontum during treatment or after to it, they can give rise to a secondary infection [11].

The microbiota of persistent and secondary infections in endodontically treated teeth differ from those in primary infections. In fact, studies using identification procedures based on phenotypes have revealed that the microbiota in persistent infections are supported by facultative anaerobic bacteria, while in primary infections, aerobic bacteria are present with facultative anaerobes [2,12].

Numerous studies have investigated the presence of microorganisms in the endodont $[2,12,13]$. The species frequently found in endodontically treated teeth are Streptococci and Enterococci [14-16]. Therefore, many studies have focused on developing effective strategies for their eradication from the root canal $[17,18]$.

Actinomyces spp. are part of the flora of the oral cavity, and have the ability to adhere to the oral tissue and thereby resist cleansing mechanisms such as salivary flow. Actinomyces spp. play an important role in the formation of dental biofilm; in fact, it has been suggested that Actinomyces species contribute to the development of diseases such as caries and periodontitis [19].

Bacterial survival is closely related to their adaptability to hostile environments; an effective survival strategy is the ability to form a biofilm, which is always present in persistent infections [20]. It is difficult to distinguish whether the microorganisms that contribute to secondary infection are those left over from primary infections, or if they are new microorganisms.

Because of the physical constraints of the root canal system, obtaining a representative sample from this site is often not an easy task. This difficulty is much more pronounced in patients undergoing remission of pulp disease, where the number of microorganisms accessible in the root canal can be low, and number of microbial cells can be lost during procedures to remove the root canal filling.

As a result, the number of sampled cells can decrease, and the prevalence of a particular species can be underestimated.

The different percentages relating to the presence of microorganisms depend on the measurement techniques used, such as PCR or culture [21,22]. The biochemical identification of bacteria is required after isolation in pure culture, although it is laborious and time-consuming. On the other hand, 
some isolated oral bacteria-for example, members of Eubacterium-are difficult to identify using morphological and biochemical methods [23], leading to the requirement of a combination of methods in order to confirm their identification biochemically; i.e., by sequencing the 16S rRNA gene.

Molecular genetic methods-in particular, PCR-have been widely used for microbial identification purposes. PCR tests are very sensitive, and can allow the identification of microbial species that are difficult to cultivate [11,24].

More information on the different bacterial associations present within the same primary and secondary endodontic lesion can help in outlining an optimal treatment strategy for eradicating the microorganisms associated with endodontic lesions.

The purpose of this review is to investigate the possible microbial associations of actinomycetes in endodontic infections. Actinomyces is one of the perpetrators of persistent intra and extraradicular infections, and knowledge regarding its possible microbial associations may be important in applying a suitable therapy for eradication. In addition, the persistence of infections on the external surface of the root apex, with the formation of a biofilm, often leads to the failure of antibiotic and endodontic therapies.

\section{Materials and Methods}

The following review was performed on the basis of PRISMA (Preferred Reporting Items for Systematic Reviews and Meta-Analysis) [25] indications. The methodology has already been adopted in other systematic reviews on the topic (Actinomyces and Propionibacterium) by the same authors [26-28].

The PICO question are the following:

- Population-patients with teeth with primary and secondary endodontic infections;

- Intervention-microbial associations with the genus Actinomyces;

- Control-patients with teeth that have no Actinomyces infections;

- Outcome - odds ratio of microbial genera that are found in association with the genus Actinomyces in primary and secondary endodontic infections.

The primary outcome of the review is to answer the following questions: Which genera of bacteria are found in association with the genus Actinomyces in primary and secondary endodontic infections? What is the odds ratio of microbial genera that are found in association with the genus Actinomyces in primary and secondary endodontic infections? Finally, which among the species of the genus Actinomyces has the greatest prevalence in endodontic lesions (secondary outcome)?

After an initial selection phase, in which records were identified in databases, the potentially eligible articles were qualitatively evaluated in order to investigate the role of bacteria in endodontic infections and in apical periodontitis, with particular attention being paid to the role of Actinomyces in endodontic infections.

\subsection{Eligibility Criteria}

Scientific studies concerning the role of bacteria in primary and secondary endodontic lesions were considered. In particular, all studies that investigated the presence of microorganisms within dental elements subject to endodontic treatment or retreatment, conducted in recent years (40 years) and published with abstracts in English, were considered potentially eligible.

We decided to choose articles published within the last 40 years because an increasing number of new bacterial species have been identified since 1980 (according to the approved lists of bacterial names in Med. J. Aust. 1980, 2, 3-4) [29].

The potentially eligible articles were finally subjected to a full-text analysis so as to verify their use for qualitative analysis and quantitative analysis.

The inclusion and exclusion criteria applied in the full-text analysis were the following:

- Studies were included if they identified both bacteria of the genus Actinomyces and bacteria of other genera in dental elements subjected to endodontic treatment or retreatment, or in the teeth subjected to apicectomy or extraction following endodontic failure; 
- Studies were excluded if they did not report the prevalence data for bacteria of the genus Actinomyces in the primary and secondary lesions of the dental elements, did not consider the microbial composition of each analyzed sample, tested the presence of only a few species of bacteria, were not written in English or were published before 1980.

\subsection{Research Methodology}

The articles were identified using electronic databases—namely PubMed and Scopus—and their bibliographies were examined and consulted in order to further identify articles.

The search for sources was conducted between 13.03.2020 and 25.03.2020.

The following search terms were used in the searches of PubMed, Scopus, EBSCO and Web of Science: "persistent intraradicular infection" OR "primary endodontic infection" (PubMed 37), "endodontic failure" OR "endodontic microbiologic" (PubMed 203), "Actinomyces" AND "endodontic" OR "apical parodontitis" (PubMed 117), "persistent intraradicular infection" (Scopus 23), "persistent extraradicular infection" (Scopus 18), "Actinomyces" AND "endodontic" (Scopus 145) "persistent extraradicular infection" (EBSCO 7), "persistent intraradicular infection" (EBSCO 14), "Actinomyces" AND "endodontic" (EBSCO 113), "persistent extraradicular infection" (Web of Science 19) "persistent intraradicular infection" (Web of Science 19) and "Actinomyces" AND "endodontic" (Web of Science 117) (Table 1). As a complement to this search, we conducted a manual evaluation of the articles included in the references of the identified full-text publications, and 51 citations were considered to be of relevance.

\subsection{Screening Methodology}

Before the identification phase of records, the keywords to be searched and their combinations were first agreed upon by the two reviewers (with the task of selecting potentially eligible articles). The records obtained were subsequently examined by two independent reviewers (M.D. and C.Q.), and a third reviewer (G.T.) acted as a decision-maker in situations of doubt.

The screening included the analysis of the title and the abstract and, in cases of doubt, a text analysis to eliminate records that were not related to the topics of the review. The articles obtained were subjected to full-text analysis by the two reviewers ( 81 articles), from which those eligible for qualitative analysis and inclusion in the meta-analysis for the two outcomes were identified.

The results sought by the two reviewers were the following:

(1) Primary outcome-which genera of bacteria are found in association with the genus Actinomyces in primary and secondary endodontic infections? What is the odds ratio of microbial genera that are found in association with the genus Actinomyces in primary and secondary endodontic infections?

(2) Secondary outcome - the determination of the prevalence of the species of the genus Actinomyces that has the greatest prevalence in endodontic lesions. 
Table 1. Complete overview of the search methodology. The overlaps were removed using EndNote 8 software. Records identified by databases: 883 ; records selected for quantitative analysis: 11 .

\begin{tabular}{|c|c|c|c|c|c|c|c|}
\hline Provider Database & Keywords & Search Details & $\begin{array}{l}\text { No. of } \\
\text { Records }\end{array}$ & $\begin{array}{c}\text { Articles after } \\
\text { Removal of } \\
\text { Overlapping } \\
\text { Articles } \\
\end{array}$ & $\begin{array}{c}\text { Number of Records } \\
\text { after Restriction by } \\
\text { Year of Publication } \\
\text { (Last } 40 \text { Years) }\end{array}$ & $\begin{array}{l}\text { Numbers of Articles } \\
\text { That Have Investigated } \\
\text { the Role of Bacteria in } \\
\text { Endodontic Infections }\end{array}$ & $\begin{array}{l}\text { Number of Studies That } \\
\text { Consider the Microbial } \\
\text { Composition of Each } \\
\text { Analyzed Sample }\end{array}$ \\
\hline PubMed & $\begin{array}{l}\text { "persistent intraradicular } \\
\text { infection" OR "primary } \\
\text { endodontic infection" }\end{array}$ & $\begin{array}{l}\text { "persistent intraradicular infection" } \\
\text { [All Fields] OR "primary } \\
\text { endodontic infection" [All Fields] }\end{array}$ & 37 & & & & \\
\hline PubMed & $\begin{array}{l}\text { "endodontic failure" OR } \\
\text { "endodontic } \\
\text { microbiologic" }\end{array}$ & $\begin{array}{l}\text { "endodontic failure" [All Fields] } \\
\text { OR (endodontic [All Fields] AND } \\
\text { microbiologic [All Fields]) }\end{array}$ & 203 & & & & \\
\hline PubMed & $\begin{array}{c}\text { "Actinomyces" AND } \\
\text { "endodontic" OR "apical } \\
\text { parodontitis" }\end{array}$ & $\begin{array}{l}\text { "Actinomyces" [All Fields] AND } \\
\text { "endodontic" [All Fields] OR } \\
\text { "apical parodontitis" [All Fields] }\end{array}$ & 117 & & & & \\
\hline Scopus & $\begin{array}{l}\text { "persistent intraradicular } \\
\text { infection" }\end{array}$ & $\begin{array}{l}\text { TITLE-ABS-KEY (persistent AND } \\
\text { interradicular AND infection) }\end{array}$ & 23 & & & & \\
\hline Scopus & $\begin{array}{l}\text { "persistent extraradicular } \\
\text { infection" }\end{array}$ & $\begin{array}{l}\text { TITLE-ABS-KEY (persistent AND } \\
\text { extravascular AND infection) }\end{array}$ & 18 & & & & \\
\hline Scopus & $\begin{array}{l}\text { "Actinomyces" AND } \\
\text { "endodontic" }\end{array}$ & $\begin{array}{l}\text { TITLE-ABS-KEY ("Actinomyces" } \\
\text { AND “endodontic") }\end{array}$ & 145 & & & & \\
\hline EBSCO & $\begin{array}{l}\text { persistent extraradicular } \\
\text { infection }\end{array}$ & & 7 & & & & \\
\hline EBSCO & $\begin{array}{l}\text { persistent intraradicular } \\
\text { infection }\end{array}$ & & 14 & & & & \\
\hline EBSCO & $\begin{array}{l}\text { "Actinomyces" AND } \\
\text { "endodontic" }\end{array}$ & & 113 & & & & \\
\hline Web of science & $\begin{array}{l}\text { persistent extraradicular } \\
\text { infection }\end{array}$ & & 19 & & & & \\
\hline Web of science & $\begin{array}{l}\text { persistent intraradicular } \\
\text { infection }\end{array}$ & & 19 & & & & \\
\hline Web of science & $\begin{array}{l}\text { "Actinomyces" AND } \\
\text { "endodontic" }\end{array}$ & & 117 & & & & \\
\hline $\begin{array}{l}\text { Articles included in the } \\
\text { references of the identified } \\
\text { full-text publications }\end{array}$ & & & 51 & & & & \\
\hline Total records & & & 883 & 475 & 462 & 81 & 11 \\
\hline
\end{tabular}




\subsection{Statistical Analysis Protocol}

A meta-analysis was conducted on five sub-groups identified among the genus bacteria that had the highest number of positive samples together with the genus Actinomyces (primary outcome). The analyzed sub-groups were the following: Streptococci, Propionibacterium, Peptostreptococci, Staphylococci and Eubacterium. With the meta-analysis of the sub-groups, odds ratios (OR) were calculated to establish whether the bacteria of the respective sub-groups were more likely to present themselves in the samples with Actinomyces than in those without Actinomyces.

The protocol with which the meta-analysis was performed is based on the indications of the Cochrane Handbook for Systematic Reviews of Interventions. It was decided to use Reviewer Manager 5.4 (Cochrane collaboration, Copenhagen, Denmark) as a software for metanalysis [30]. In particular, pooled odds ratios (OR) and their $95 \%$ confidence intervals were calculated, and the inverse of variance test was applied to test for differences in overall effects between groups. The presence of heterogeneity was assessed by calculating the Higgins Index $\left(I^{2}\right)$; if the measure proved to be higher than $50 \%$, the rate of heterogeneity was considered to be high. The pooled results of meta-analysis were represented via forest plots for each of the analyzed sub-groups.

The risk of bias in the studies was calculated following the guidelines reported in the Newcastle-Ottawa Scale (NOS) for assessing the quality of studies in meta-analyses [31].

The risk of bias between studies was assessed graphically through the use of funnel plots and the calculation of heterogeneity determined through the Rev-manager 5.4 software.

A meta-regression was conducted with the use of Open Meta-Analyst version 10 (Tufts University, Medford, MA, USA) for those sub-groups that had high heterogeneity, reporting the risk of bias as a covariant.

\section{Results}

From searches in the PubMed, Scopus, EBSCO and Web of Science databases, 883 records were identified; furthermore, 51 articles included in the references of the identified full-text publications were selected. With the use of EndNote software, the overlaps were removed, resulting in 475 records. After the elimination of articles prior to 1980, 462 records remained. With the application of the eligibility criteria (all studies that studied the presence of bacteria in endodontic infection), we retained 81 articles.

Applying the inclusion and exclusion criteria, we retained 11 articles in the meta-analysis.

All articles were analyzed according to the primary and secondary outcomes as defined above.

All selection and screening procedures are described in the flowchart shown in Figure 1.

\subsection{Study Characteristics and Data Extraction}

The studies included for the quantitative analysis were those of Sunde et al., 2002 [32]; Siqueira et al., 2004 [33]; Ledezma-Rasillo et al., 2010 [34]; Sundqvist et al., 1989 [35]; Abou-Rass et al., 1998 [36]; Niazi et al., 2010 [37]; Fujii et al., 2009 [38]; Pinheiro et al., 2003 [14]; Sjogren et al., 1997 [3]; Fukushima et al., 1990 [39]; and Debelian et al., 1995 [40].

The extraction of the data and the methods by which they have been reported follow the indications of the Cochrane Handbook for Systematic Reviews of Interventions, chapter 7 (selection of studies and data collection); specifically, from pages 156 to 182.

The extracted data included the bacterium species in the infection along with the bacterial species of the genus Actinomyces investigated (genus and species), the article information (data, author and journal), the number of samples examined, the types of samples (tooth in pulpitis or apical periodontitis, necrotic or vital tooth, tooth previously treated endodontically, endodontic canal, and tooth with failure subject to extraction or endodontic surgery), the number of samples for pathology in the presence of Actinomyces, and the bacterium identification method (culture or PCR). 


\section{PRISMA 2009 Flow Diagram}
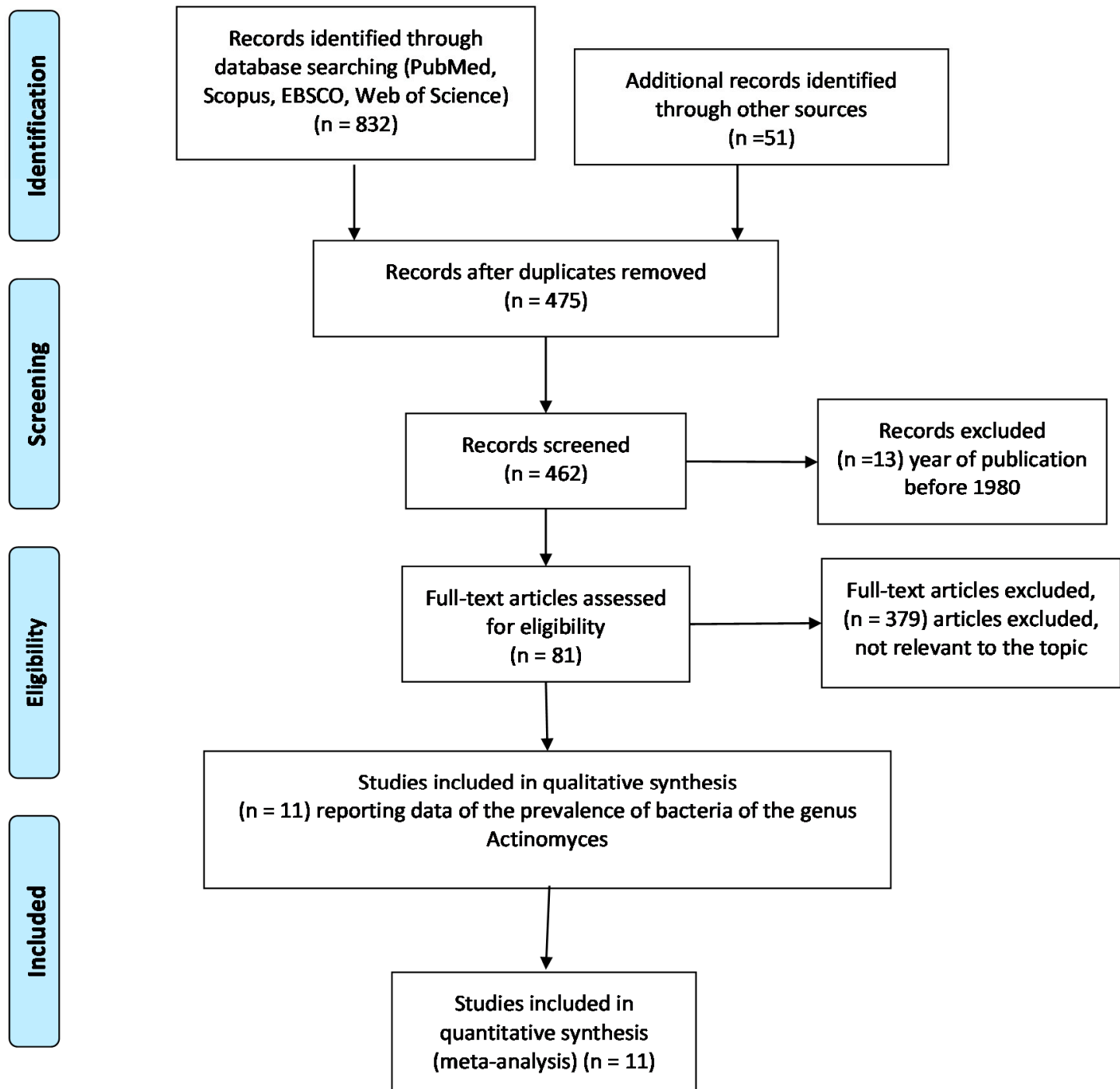

Figure 1. Flowchart of the different phases of the systematic review.

The data extracted for the two outcomes are shown in Tables 2 and 3.

Table 2 reports the number of samples of a particular bacterial genus found in association with Actinomyces, compared with the number of samples of Actinomyces. Then, the number of samples with that particular genus, compared with all the samples analyzed for each article, is reported. Table 3 reports the number of samples in which each Actinomyces species is present in each article.

For the studies selected for qualitative and quantitative analysis, a total of 331 samples were analyzed, and bacteria of the genus Actinomyces were found in 58 samples. For each sample, the microbial composition was available.

For the primary outcome, the bacterial genera present in the infections were considered together with species of the genus Actinomyces, and the prevalence relative to the infected samples together with Actinomyces was calculated in addition to the absolute prevalence relative to all the samples analyzed in each study (Table 4). 
Table 2. Primary outcome: prevalence of microbial genera in the samples in association with bacteria of the genus Actinomyces, and their prevalence in the total samples analyzed in each article.

\begin{tabular}{|c|c|c|c|c|c|c|}
\hline First Author, Date, Journal & $\begin{array}{l}\text { Type of Endodontic } \\
\text { Lesion }\end{array}$ & $\begin{array}{l}\text { Total Number } \\
\text { of Samples }\end{array}$ & $\begin{array}{l}\text { Number of Samples } \\
\text { with Actinomyces }\end{array}$ & $\begin{array}{l}\text { Prevalence of Microbial } \\
\text { Genera in Association with } \\
\text { Genus Actinomyces }\end{array}$ & $\begin{array}{c}\text { Prevalence of Microbial } \\
\text { Genera in the Total Samples } \\
\text { Analyzed }\end{array}$ & $\begin{array}{l}\text { Identification } \\
\text { Method }\end{array}$ \\
\hline $\begin{array}{c}\text { Sunde, 2002, Journal of } \\
\text { Endodontics }\end{array}$ & $\begin{array}{l}\text { Refractory apical } \\
\text { periodontitis }\end{array}$ & 36 & 5 & $\begin{array}{c}\text { Clostridium: } 2 / 5 \\
\text { Propionibacterium: } 3 / 5 \\
\text { Gemella: } 1 / 5 \\
\text { Peptostreptococcus: } 1 / 5 \\
\text { Vibrio: } 1 / 5 \\
\text { Leptotrichia: } 1 / 5 \\
\text { Staphylococcus: } 2 / 5 \\
\text { Streptococcus: } 1 / 5\end{array}$ & $\begin{array}{c}\text { Clostridium: } 2 / 36 \\
\text { Propionibacterium: } 3 / 36 \\
\text { Gemella: } 2 / 36 \\
\text { Peptostreptococcus: } 1 / 36 \\
\text { Vibrio: } 1 / 36 \\
\text { Leptotrichia: } 1 / 36 \\
\text { Staphylococcus: } 3 / 36 \\
\text { Streptococcus: } 2 / 36\end{array}$ & Culture \\
\hline $\begin{array}{l}\text { Siqueira, 2004, Oral surgery, } \\
\text { oral medicine, oral } \\
\text { pathology, oral radiology } \\
\text { and endodontics }\end{array}$ & $\begin{array}{l}\text { Root-filled teeth with } \\
\text { persistent } \\
\text { periradicular lesions }\end{array}$ & 22 & 1 & $\begin{array}{c}\text { Propionibacterium, } \\
\text { Pseudoramibacter, Enterococcus }\end{array}$ & $\begin{array}{l}\text { Propionibacterium: 11/22 } \\
\text { Pseudoramibacter: } 12 / 22 \\
\text { Enterococcus: } 17 / 22\end{array}$ & PCR \\
\hline $\begin{array}{l}\text { Ledezma-Rasillo, 2010, The } \\
\text { Journal of clinical pediatric } \\
\text { dentistry }\end{array}$ & $\begin{array}{l}\text { Primary teeth with } \\
\text { necrotic pulps }\end{array}$ & 21 & 6 & $\begin{array}{l}\text { Bifidobacterium: 5/6 } \\
\text { Veillonella: } 1 / 6 \\
\text { Clostridium: } 3 / 6 \\
\text { Streptococcus: } 2 / 6 \\
\text { Gemella: } 1 / 6\end{array}$ & $\begin{array}{l}\text { Bifidobacterium: } 17 / 21 \\
\text { Veillonella: } 2 / 21 \\
\text { Clostridium: } 7 / 21 \\
\text { Streptococcus: } 6 / 21 \\
\text { Gemella: } 1 / 21\end{array}$ & Culture \\
\hline $\begin{array}{l}\text { Sundqvist, 1989, Journal of } \\
\text { endodontics }\end{array}$ & $\begin{array}{l}\text { Teeth with apical } \\
\text { periodontitis }\end{array}$ & 72 & 5 & $\begin{array}{l}\text { Peptostreptococcus: } 5 / 5 \\
\text { Lactobacillus: } 2 / 5 \\
\text { Bacteroides: } 5 / 5 \\
\text { Wolinella: } 1 / 5 \\
\text { Streptococcus: } 1 / 5 \\
\text { Eubacterium: } 3 / 5 \\
\text { Fusobacterium: } 3 / 5\end{array}$ & $\begin{array}{c}\text { Peptostreptococcus: } 19 / 72 \\
\text { Lactobacillus: } 12 / 72 \\
\text { Bacteroides: } 22 / 72 \\
\text { Wolinella: } 6 / 72 \\
\text { Streptococcus: } 8 / 72 \\
\text { Eubacterium: } 17 / 72 \\
\text { Fusobacterium: } 16 / 72\end{array}$ & Culture \\
\hline $\begin{array}{c}\text { Abou-Rass, 1998, } \\
\text { International endodontic } \\
\text { journal }\end{array}$ & $\begin{array}{l}\text { Closed periapical } \\
\text { lesions associated } \\
\text { with refractory } \\
\text { endodontic therapy }\end{array}$ & 13 & 6 & $\begin{array}{c}\text { Streptococcus: } 3 / 6 \\
\text { Staphylococcus: } 1 / 6 \\
\text { Peptostreptococcus: } 1 / 6 \\
\text { Gram-negative enteric rods: } 1 / 6 \\
\text { Propionibacterium: } 1 / 6 \\
\text { Porphyromonas: } 1 / 6 \\
\text { Fusobacterium: } 1 / 6\end{array}$ & $\begin{array}{c}\text { Streptococcus:7/13 } \\
\text { Staphylococcus: } 4 / 13 \\
\text { Peptostreptococcus: } 1 / 13 \\
\text { Gram-negative enteric rods: } 1 / 13 \\
\text { Propionibacterium: } 6 / 13 \\
\text { Porphyromonas: } 1 / 13 \\
\text { Fusobacterium: } 1 / 13\end{array}$ & Culture \\
\hline
\end{tabular}


Table 2. Cont.

\begin{tabular}{|c|c|c|c|c|c|c|}
\hline First Author, Date, Journal & $\begin{array}{c}\text { Type of Endodontic } \\
\text { Lesion }\end{array}$ & $\begin{array}{c}\text { Total Number } \\
\text { of Samples }\end{array}$ & $\begin{array}{l}\text { Number of Samples } \\
\text { with Actinomyces }\end{array}$ & $\begin{array}{c}\text { Prevalence of Microbial } \\
\text { Genera in Association with } \\
\text { Genus Actinomyces }\end{array}$ & $\begin{array}{c}\text { Prevalence of Microbial } \\
\text { Genera in the Total Samples } \\
\text { Analyzed }\end{array}$ & $\begin{array}{l}\text { Identification } \\
\text { Method }\end{array}$ \\
\hline $\begin{array}{l}\text { Niazi, 2010, Journal of } \\
\text { clinical microbiology }\end{array}$ & $\begin{array}{c}\text { Refractory } \\
\text { endodontic lesions (9 } \\
\text { with abscesses and } 11 \\
\text { without abscesses) }\end{array}$ & 20 & 12 & $\begin{array}{c}\text { Gemella: } 3 / 12 \\
\text { Propionibacterium: } 10 / 12 \\
\text { Staphylococcus: } 9 / 12 \\
\text { Streptococcus: } 11 / 12 \\
\text { Clostridium: } 1 / 12 \\
\text { Capnocytophaga: } 3 / 12 \\
\text { Prevotella: } 4 / 12 \\
\text { Selenomonas: } 3 / 12 \\
\text { Olsenella: } 4 / 12 \\
\text { Bifidobacterium: } 1 / 12 \\
\text { Lactobacillus: } 1 / 12 \\
\text { Abiotrophia: } 1 / 12 \\
\text { Granulicatella: } 2 / 12 \\
\text { Kocuria: } 1 / 12 \\
\text { Micrococcus: } 1 / 12 \\
\text { Rothia: } 2 / 12 \\
\text { Eubacterium: } 4 / 12 \\
\text { Parvimonas: } 2 / 12 \\
\text { Solobacterium: } 2 / 12 \\
\text { Veillonella: } 3 / 12 \\
\text { Enterococcus: } 1 / 12 \\
\text { Bacteroides: } 1 / 12 \\
\text { Desulfovibrio: } 1 / 12 \\
\text { Lautropia: } 1 / 12 \\
\text { Phascolarctobacterium: } 1 / 12 \\
\text { Catonella: } 1 / 12 \\
\text { Oribacterium: } 1 / 12 \\
\text { Slackia: } 2 / 12 \\
\text { Pseudoramibacter: } 3 / 12 \\
\text { Mogibacterium: } 3 / 12 \\
\text { Atopobium: } 2 / 12 \\
\text { Dialister: } 3 / 12 \\
\text { Porphyromonas: } 2 / 12 \\
\text { Tanerella: } 1 / 12 \\
\text { Campylobacter: } 1 / 12 \\
\text { (a) }\end{array}$ & $\begin{array}{c}\text { Gemella: } 5 / 20 \\
\text { Propionibacterium: } 18 / 20 \\
\text { Staphylococcus: } 15 / 20 \\
\text { Streptococcus: } 15 / 20 \\
\text { Clostridium: } 2 / 20 \\
\text { Capnocytophaga: } 3 / 20 \\
\text { Prevotella: } 7 / 20 \\
\text { Selenomonas: } 3 / 20 \\
\text { Olsenella: } 5 / 20 \\
\text { Bifidobacterium: } 2 / 20 \\
\text { Lactobacillus: } 1 / 20 \\
\text { Abiotrophia: } 1 / 20 \\
\text { Granulicatella: } 2 / 20 \\
\text { Kocuria: } 1 / 20 \\
\text { Micrococcus: } 2 / 20 \\
\text { Rothia: } 2 / 20 \\
\text { Eubacterium: } 6 / 20 \\
\text { Parvimonas: } 2 / 20 \\
\text { Solobacterium: } 3 / 20 \\
\text { Veillonella: } 4 / 20 \\
\text { Enterococcus: } 3 / 20 \\
\text { Bacteroides: } 1 / 20 \\
\text { Desulfovibrio: } 1 / 20 \\
\text { Lautropia: } 1 / 20 \\
\text { Phascolarctobacterium: } 1 / 20 \\
\text { Catonella: } 1 / 20 \\
\text { Oribacterium: } 1 / 20 \\
\text { Slackia: } 4 / 20 \\
\text { Pseudoramibacter: } 4 / 20 \\
\text { Mogibacterium: } 6 / 20 \\
\text { Atopobium: } 2 / 20 \\
\text { Dialister: } 5 / 20 \\
\text { Porphyromonas:2/20 } \\
\text { Tanerella: } 4 / 20 \\
\text { Campylobacter: } 2 / 20\end{array}$ & PCR \\
\hline
\end{tabular}


Table 2. Cont.

\begin{tabular}{|c|c|c|c|c|c|c|}
\hline First Author, Date, Journal & $\begin{array}{l}\text { Type of Endodontic } \\
\text { Lesion }\end{array}$ & $\begin{array}{c}\text { Total Number } \\
\text { of Samples }\end{array}$ & $\begin{array}{l}\text { Number of Samples } \\
\text { with Actinomyces }\end{array}$ & $\begin{array}{l}\text { Prevalence of Microbial } \\
\text { Genera in Association with } \\
\text { Genus Actinomyces }\end{array}$ & $\begin{array}{c}\text { Prevalence of Microbial } \\
\text { Genera in the Total Samples } \\
\text { Analyzed }\end{array}$ & $\begin{array}{l}\text { Identification } \\
\text { Method }\end{array}$ \\
\hline $\begin{array}{l}\text { Fujii, 2009, Oral } \\
\text { microbiology and } \\
\text { immunology }\end{array}$ & $\begin{array}{l}\text { Apical periodontitis } \\
\text { lesions of obturated } \\
\text { teeth }\end{array}$ & 20 & 2 & $\begin{array}{l}\text { Fusobacterium: } 1 / 2 \\
\quad \text { Slackia: } 1 / 2 \\
\text { Staphylococcus: } 1 / 2 \\
\text { Streptococcus: } 2 / 2 \\
\text { Stenotrophomonas: } 1 / 2 \\
\text { Prevotella: } 1 / 2\end{array}$ & $\begin{array}{c}\text { Fusobacterium: } 5 / 20 \\
\text { Slackia: } 1 / 20 \\
\text { Staphylococcus: } 8 / 20 \\
\text { Streptococcus: } 5 / 20 \\
\text { Stenotrophomonas: } 1 / 20 \\
\text { Prevotella: } 4 / 20\end{array}$ & PCR \\
\hline $\begin{array}{c}\text { Pinheiro, 2003, } \\
\text { International endodontic } \\
\text { journal }\end{array}$ & $\begin{array}{l}\text { Root-filled teeth with } \\
\text { apical periodontitis }\end{array}$ & 60 & 9 & $\begin{array}{c}\text { Streptococcus: } 4 / 9 \\
\text { Enterococcus: } 2 / 9 \\
\text { Prevotella: } 2 / 9 \\
\text { Peptostreptococcus: } 2 / 9 \\
\text { Bifidobacterium: } 1 / 9 \\
\text { Veillonella: } 3 / 9 \\
\text { Candida: } 1 / 9 \\
\text { Propionibacterium: } 1 / 9 \\
\text { Fusobacterium: } 1 / 9 \\
\text { Gemella: } 3 / 9 \\
\text { Haemophilus: } 1 / 9 \\
\text { Staphylococcus: } 1 / 9\end{array}$ & $\begin{array}{c}\text { Streptococcus: 17/60 } \\
\text { Enterococcus: 28/60 } \\
\text { Prevotella: } 6 / 60 \\
\text { Peptostreptococcus: 9/60 } \\
\text { Bifidobacterium: 1/60 } \\
\text { Veillonella: 4/60 } \\
\text { Candida: } 2 / 60 \\
\text { Propionibacterium: 5/60 } \\
\text { Fusobacterium: } 3 / 60 \\
\text { Gemella: 4/60 } \\
\text { Haemophilus: } 1 / 60 \\
\text { Staphylococcus: } 3 / 60\end{array}$ & Culture \\
\hline $\begin{array}{l}\text { Sjogren, 1997, International } \\
\text { endodontic journal }\end{array}$ & Apical periodontitis & 20 & 3 & $\begin{array}{c}\text { Prevotella: } 1 / 3 \\
\text { Eubacterium: } 1 / 3 \\
\text { Campylobacter: } 1 / 3 \\
\text { Peptostreptococcus: } 1 / 3\end{array}$ & $\begin{array}{c}\text { Prevotella: } 3 / 20 \\
\text { Eubacterium: } 9 / 20 \\
\text { Campylobacter: } 4 / 20 \\
\text { Peptostreptococcus: } 5 / 20\end{array}$ & Culture \\
\hline $\begin{array}{l}\text { Fukushima, 1990, Journal } \\
\text { of endodontics }\end{array}$ & Untreated cases & 21 & 4 & $\begin{array}{l}\text { Propionibacterium: } 3 / 4 \\
\text { Lactobacillus: } 3 / 4 \\
\text { Eubacterium: } 2 / 4 \\
\text { Peptostreptococcus: } 3 / 4 \\
\text { Peptococcus: } 1 / 4\end{array}$ & $\begin{array}{c}\text { Propionibacterium: 4/21 } \\
\text { Lactobacillus: } 5 / 21 \\
\text { Eubacterium: } 6 / 21 \\
\text { Peptostreptococcus: } 5 / 21 \\
\text { Peptococcus: } 2 / 21\end{array}$ & Culture \\
\hline
\end{tabular}


Table 2. Cont.

\begin{tabular}{|c|c|c|c|c|c|c|}
\hline First Author, Date, Journal & $\begin{array}{c}\text { Type of Endodontic } \\
\text { Lesion }\end{array}$ & $\begin{array}{c}\text { Total Number } \\
\text { of Samples }\end{array}$ & $\begin{array}{l}\text { Number of Samples } \\
\text { with Actinomyces }\end{array}$ & $\begin{array}{l}\text { Prevalence of Microbial } \\
\text { Genera in Association with } \\
\text { Genus Actinomyces }\end{array}$ & $\begin{array}{c}\text { Prevalence of Microbial } \\
\text { Genera in the Total Samples } \\
\text { Analyzed }\end{array}$ & $\begin{array}{l}\text { Identification } \\
\text { Method }\end{array}$ \\
\hline $\begin{array}{c}\text { Debelian et al., 1995, } \\
\text { Endodontics \& Dental } \\
\text { Traumatology }\end{array}$ & $\begin{array}{l}\text { Teeth with } \\
\text { asymptomatic apical } \\
\text { periodontitis }\end{array}$ & 26 & 5 & $\begin{array}{c}\text { Propionibacterium: 1/5 } \\
\text { Prevotella: } 2 / 5 \\
\text { Eubacterium: } 3 / 5 \\
\text { Campylobacter: } 1 / 5 \\
\text { Veillonella: } 1 / 5 \\
\text { Lactobacillus: } 1 / 5 \\
\text { Streptococcus: } 2 / 5 \\
\text { Porphyromonas: } 1 / 5 \\
\text { Fusobacterium: } 1 / 5 \\
\text { Clostridium: } 1 / 5 \\
\text { Peptostreptococcus: } 1 / 5 \\
\text { Saccharomyces: } 1 / 5\end{array}$ & $\begin{array}{c}\text { Propionibacterium: 4/26 } \\
\text { Prevotella: 5/26 } \\
\text { Eubacterium: } 6 / 26 \\
\text { Campylobacter: } 1 / 26 \\
\text { Veillonella: } 2 / 26 \\
\text { Lactobacillus: } 1 / 26 \\
\text { Streptococcus: } 5 / 26 \\
\text { Porphyromonas: } 2 / 26 \\
\text { Fusobacterium: } 4 / 26 \\
\text { Clostridium: } 1 / 26 \\
\text { Peptostreptococcus: } 3 / 26 \\
\text { Saccharomyces: } 1 / 26\end{array}$ & Culture \\
\hline
\end{tabular}

Table 3. Secondary outcome (prevalence of species of the genus Actinomyces given the total number of samples analyzed in each article).

\begin{tabular}{|c|c|c|c|c|c|}
\hline First Author, Date, Journal & $\begin{array}{l}\text { Type of Endodontic } \\
\text { Lesion }\end{array}$ & $\begin{array}{l}\text { Total Number } \\
\text { of Samples }\end{array}$ & $\begin{array}{l}\text { Number of Samples } \\
\text { with Actinomyces }\end{array}$ & $\begin{array}{c}\text { Prevalence of Individual Species of the Genus } \\
\text { Actinomyces, Given the Total Number of } \\
\text { Analyzed Samples }\end{array}$ & $\begin{array}{l}\text { Identification } \\
\text { Method }\end{array}$ \\
\hline Sunde, 2002, Journal of endodontics & $\begin{array}{l}\text { refractory apical } \\
\text { periodontitis }\end{array}$ & 36 & 5 & $\begin{array}{c}\text { Actinomyces israelii: } 3 / 36 \\
\text { Actinomyces viscosus: } 2 / 36 \\
\text { Actinomyces meyeri: } 1 / 36 \\
\text { Actinomyces naeslundii: } 1 / 36\end{array}$ & Culture \\
\hline $\begin{array}{l}\text { Siqueira, 2004, Oral surgery, oral } \\
\text { medicine, oral pathology, oral } \\
\text { radiology, and endodontics }\end{array}$ & $\begin{array}{l}\text { Root-filled teeth with } \\
\text { persistent periradicular } \\
\text { lesions }\end{array}$ & 22 & 1 & Actinomyces radicidentis: $1 / 22$ & PCR \\
\hline $\begin{array}{l}\text { Ledezma-Rasillo, 2010, The Journal } \\
\text { of clinical pediatric dentistry }\end{array}$ & $\begin{array}{l}\text { Primary teeth with } \\
\text { necrotic pulps }\end{array}$ & 21 & 6 & $\begin{array}{c}\text { Actinomyces israelii: } 4 / 21 \\
\text { Actinomyces naeslundii: } 2 / 21\end{array}$ & Culture \\
\hline $\begin{array}{c}\text { Sundqvist, 1989, Journal of } \\
\text { endodontics }\end{array}$ & $\begin{array}{l}\text { Teeth with apical } \\
\text { periodontitis }\end{array}$ & 72 & 5 & Actinomyces species: 5/72 & Culture \\
\hline $\begin{array}{l}\text { Abou-Rass, 1998, International } \\
\text { endodontic journal }\end{array}$ & $\begin{array}{l}\text { Closed periapical lesions } \\
\text { associated with refractory } \\
\text { endodontic therapy }\end{array}$ & 13 & 6 & $\begin{array}{c}\text { Actinomyces sp. I: 1/13 } \\
\text { Actinomyces sp. II: } 1 / 13 \\
\text { Actinomyces sp.: 5/13 }\end{array}$ & Culture \\
\hline
\end{tabular}


Table 3. Cont.

\begin{tabular}{|c|c|c|c|c|c|}
\hline First Author, Date, Journal & $\begin{array}{l}\text { Type of Endodontic } \\
\text { Lesion }\end{array}$ & $\begin{array}{c}\text { Total Number } \\
\text { of Samples }\end{array}$ & $\begin{array}{l}\text { Number of Samples } \\
\text { with Actinomyces }\end{array}$ & $\begin{array}{c}\text { Prevalence of Individual Species of the Genus } \\
\text { Actinomyces, Given the Total Number of } \\
\text { Analyzed Samples }\end{array}$ & $\begin{array}{l}\text { Identification } \\
\text { Method }\end{array}$ \\
\hline $\begin{array}{l}\text { Niazi, 2010, Journal of clinical } \\
\text { microbiology }\end{array}$ & $\begin{array}{l}\text { Refractory endodontic } \\
\text { lesions ( } 9 \text { with abscesses } \\
\text { and } 11 \text { without abscesses })\end{array}$ & 20 & 12 & $\begin{array}{c}\text { Actinomyces gerencseriae oral taxon } 618: 1 / 20 \\
\text { Actinomyces sp. oral clone CT047: } 1 / 20 \\
\text { Actinomyces massiliensis: } 1 / 20 \\
\text { Actinomyces meyeri: } 1 / 36 \\
\text { Actinomyces radicidentis: } 1 / 36 \\
\text { Actinomyces sp. oral taxon } 169 \text { clone AG004: } 3 / 36 \\
\text { Actinomyces israelii: } 1 / 36 \\
\text { Actinomyces sp. oral clone JA063: } 1 / 36 \\
\text { Actinomyces sp. oral taxon } 181 \text { strain Hal1065: } 1 / 36 \\
\text { Actinomyces strain B27SC: } 2 / 36 \\
\text { Actinomyces strain C29KA: } 1 / 36\end{array}$ & PCR \\
\hline $\begin{array}{c}\text { Fujii, 2009, Oral microbiology and } \\
\text { immunology }\end{array}$ & $\begin{array}{l}\text { Apical periodontitis } \\
\text { lesions of obturated teeth }\end{array}$ & 20 & 2 & Actinomyces naeslundii: 2/20 & PCR \\
\hline $\begin{array}{l}\text { Pinheiro, 2003, International } \\
\text { endodontic journal }\end{array}$ & $\begin{array}{l}\text { Root-filled teeth with } \\
\text { apical periodontitis }\end{array}$ & 60 & 9 & $\begin{array}{c}\text { A. naeslundii: } 4 / 60 \\
\text { A. viscosus: } 3 / 60 \\
\text { A. odontolyticus: } 3 / 60\end{array}$ & Culture \\
\hline $\begin{array}{l}\text { Sjogren, 1997, International } \\
\text { endodontic journal }\end{array}$ & Apical periodontitis & 20 & 3 & $\begin{array}{c}\text { Actinomyces israelii: } 2 / 20 \\
\text { Actinomyces odontolyticus: } 1 / 20 \\
\text { Actinomyces naeslundii: } 1 / 20\end{array}$ & Culture \\
\hline $\begin{array}{l}\text { Fukushima, 1990, Journal of } \\
\text { endodontics }\end{array}$ & Untreated cases & 21 & 4 & $\begin{array}{c}\text { Actinomyces israelii: } 2 / 21 \\
\text { Actinomyces viscosus: } 2 / 21 \\
\text { A. meyeri: } 1 / 21\end{array}$ & Culture \\
\hline $\begin{array}{l}\text { Debelian et al., 1995, Endodontics \& } \\
\text { Dental Traumatology }\end{array}$ & $\begin{array}{l}\text { Teeth with asymptomatic } \\
\text { apical periodontitis }\end{array}$ & 26 & 5 & $\begin{array}{c}\text { Actinomyces israelii: } 3 / 26 \\
\text { Actinomyces naeslundii: } 1 / 26 \\
\text { Actinomyces odontolyticus: } 1 / 26\end{array}$ & Culture \\
\hline
\end{tabular}


Table 4. Total prevalence of bacterial genera in association with Actinomyces with respect to all samples, as well as the total number of samples for all articles selected for this review. The total number of positive samples for each single bacterium is also reported.

\begin{tabular}{|c|c|c|c|}
\hline Bacterial Genus & $\begin{array}{l}\text { Prevalence in Samples That Were } \\
\text { Associated with Actinomyces, } \\
\text { Given the Total Number of } \\
\text { Samples for All Articles Selected } \\
\text { for This Review }\end{array}$ & $\begin{array}{c}\text { Prevalence in Samples, } \\
\text { Given the Total } \\
\text { Number of Samples for } \\
\text { All Articles Selected for } \\
\text { This Review }\end{array}$ & $\begin{array}{c}\text { Number of } \\
\text { Articles Reporting } \\
\text { This Genus }\end{array}$ \\
\hline Clostridium & $7 / 58$ & $12 / 331(3.6 \%)$ & 4 \\
\hline Propionibacterium & $20 / 58$ & $51 / 331(15.4 \%)$ & 7 \\
\hline Gemella & $8 / 58$ & $12 / 331(3.6 \%)$ & 4 \\
\hline Peptostreptococcus & $14 / 58$ & $43 / 331(13 \%)$ & 7 \\
\hline Vibrio & $1 / 58$ & $1 / 331(0.3 \%)$ & 1 \\
\hline Leptotrichia & $1 / 58$ & $1 / 331(0.3 \%)$ & 1 \\
\hline Staphylococcus & $14 / 58$ & $33 / 331(10 \%)$ & 5 \\
\hline Streptococcus & $26 / 58$ & $65 / 331(19.6 \%)$ & 8 \\
\hline Pseudoramibacter & $4 / 58$ & $16 / 331(4.8 \%)$ & 2 \\
\hline Enterococcus & $4 / 58$ & $48 / 331(14.5 \%)$ & 3 \\
\hline Bifidobacterium & $7 / 58$ & $20 / 331(6 \%)$ & 3 \\
\hline Veillonella & $8 / 58$ & $12 / 331(3.6 \%)$ & 4 \\
\hline Lactobacillus & $7 / 58$ & $19 / 331(5.7 \%)$ & 4 \\
\hline Bacteroides & $6 / 58$ & $23 / 331(6.9 \%)$ & 2 \\
\hline Wolinella & $1 / 58$ & $6 / 331(1.8 \%)$ & 1 \\
\hline Eubacterium & $13 / 58$ & $44 / 331(13.3 \%)$ & 5 \\
\hline Fusobacterium & $7 / 58$ & $29 / 331(8: 8 \%)$ & 5 \\
\hline Gram-negative enteric rods & $1 / 58$ & $1 / 331(0.3 \%)$ & 1 \\
\hline Porphyromonas & $4 / 58$ & $5 / 331(1.5 \%)$ & 3 \\
\hline Capnocytophaga & $3 / 58$ & $3 / 331(0.9 \%)$ & 1 \\
\hline Prevotella & $10 / 58$ & $25 / 331(7.5 \%)$ & 5 \\
\hline Selenomonas & $3 / 58$ & $3 / 331(0.9 \%)$ & 1 \\
\hline Olsenella & $4 / 58$ & $5 / 331(1.5 \%)$ & 1 \\
\hline Abiotrophia & $1 / 58$ & $1 / 331(0.3 \%)$ & 1 \\
\hline Granulicatella & $2 / 58$ & $2 / 331(0.6 \%)$ & 1 \\
\hline Kocuria & $1 / 58$ & $1 / 331(0.3 \%)$ & 1 \\
\hline Micrococcus & $1 / 58$ & $2 / 331(0.6 \%)$ & 1 \\
\hline Rothia & $2 / 58$ & $2 / 331(0.6 \%)$ & 1 \\
\hline Parvimonas & $2 / 58$ & $2 / 331(0.6 \%)$ & 1 \\
\hline Solobacterium & $2 / 58$ & $3 / 331(0.9 \%)$ & 1 \\
\hline Desulfovibrio & $1 / 58$ & $1 / 331(0.3 \%)$ & 1 \\
\hline Lautropia & $1 / 58$ & $1 / 331(0.3 \%)$ & 1 \\
\hline Phascolarctobacterium & $1 / 58$ & $1 / 331(0.3 \%)$ & 1 \\
\hline Catonella & $1 / 58$ & $1 / 331(0.3 \%)$ & 1 \\
\hline Oribacterium & $1 / 58$ & $1 / 331(0.3 \%)$ & 1 \\
\hline Slackia & $3 / 58$ & $5 / 331(1.5 \%)$ & 2 \\
\hline Mogibacterium & $3 / 58$ & $6 / 331(1.8 \%)$ & 1 \\
\hline Atopobium & $2 / 58$ & $2 / 331(0.6 \%)$ & 1 \\
\hline Dialister & $3 / 58$ & $5 / 331(1.5 \%)$ & 1 \\
\hline Tanerella & $1 / 58$ & $4 / 331(1.2 \%)$ & 1 \\
\hline Campylobacter & $3 / 58$ & $7 / 331(2.1 \%)$ & 3 \\
\hline Stenotrophomonas & $1 / 58$ & $1 / 331(0.3 \%)$ & 1 \\
\hline Candida & $1 / 58$ & $2 / 331(0.6 \%)$ & 1 \\
\hline Haemophilus & $1 / 58$ & $1 / 331(0.3 \%)$ & 1 \\
\hline Peptococcus & $1 / 58$ & $2 / 331(0.6 \%)$ & 1 \\
\hline Saccharomyces & $1 / 58$ & $1 / 331(0.3 \%)$ & 1 \\
\hline
\end{tabular}

In some studies, only a cultural search of bacterial species was carried out; thus, an analysis by sub-group (cultures and PCR) was also carried out to remedy an evident limit of the review, as shown in Table 5. 
Table 5. Data referring to the two sub-groups (culture and PCR).

\begin{tabular}{ccccc}
\hline & \multicolumn{2}{c}{ Sub-Group Culture } & \multicolumn{2}{c}{ Sub-Group PCR } \\
\cline { 2 - 5 } Bacterial Genus & $\begin{array}{c}\text { Prevalence in } \\
\text { Samples That } \\
\text { Were Associated } \\
\text { with Actinomyces }\end{array}$ & $\begin{array}{c}\text { Prevalence in } \\
\text { Samples, Given the } \\
\text { Total of Number of } \\
\text { Samples }\end{array}$ & $\begin{array}{c}\text { Prevalence in } \\
\text { Samples That } \\
\text { Were Associated } \\
\text { with Actinomyces }\end{array}$ & $\begin{array}{c}\text { Prevalence in } \\
\text { Samples, Given the } \\
\text { Total of Number of } \\
\text { Samples }\end{array}$ \\
\hline Clostridium & $6 / 16$ & $10 / 83$ & $1 / 12$ & $2 / 20$ \\
Propionibacterium & $9 / 29$ & $22 / 156$ & $11 / 13$ & $29 / 42$ \\
Streptococcus & $13 / 36$ & $43 / 228$ & $13 / 14$ & $20 / 40$ \\
Peptostreptococcus & $14 / 37$ & $43 / 212$ & - & - \\
Staphylococcus & $13 / 34$ & $25 / 129$ & $1 / 2$ & $8 / 20$ \\
Eubacterium & $9 / 17$ & $38 / 139$ & $4 / 12$ & $6 / 20$ \\
Fusobacterium & $6 / 25$ & $24 / 171$ & $1 / 2$ & $5 / 20$ \\
Prevotella & $9 / 29$ & $21 / 126$ & $1 / 2$ & $4 / 20$ \\
Veillonella & $5 / 20$ & $8 / 107$ & $3 / 9$ & $4 / 20$ \\
Lactobacillus & $6 / 14$ & $18 / 119$ & $1 / 12$ & $1 / 20$ \\
enterococcus & $2 / 9$ & $28 / 60$ & $2 / 13$ & $20 / 42$ \\
Porphyromonas & $2 / 11$ & $3 / 39$ & $2 / 12$ & $2 / 20$ \\
Campylobacter & $2 / 8$ & $5 / 46$ & $1 / 12$ & $2 / 20$ \\
Bifidobacterium & $6 / 15$ & $18 / 81$ & $1 / 12$ & $2 / 20$ \\
\hline
\end{tabular}

For the secondary outcome, the prevalence of each individual species of Actinomyces was calculated and compared with the total number of analyzed samples (Table 6).

Table 6. Prevalence of the individual Actinomyces species, given the total number of samples for all articles selected for this review. We have the greatest number of positive samples with Actinomyces israelii and Actinomyces naeslundii.

\begin{tabular}{ccc}
\hline Species of the Genus Actinomyces & $\begin{array}{c}\text { Prevalence of the Actinomyces Species } \\
\text { in Samples for the Total Number of } \\
\text { Analyzed Samples for All Articles }\end{array}$ & $\begin{array}{c}\text { Number of } \\
\text { Articles Reporting } \\
\text { This Species }\end{array}$ \\
\hline Actinomyces israelii & $15 / 331(4.5 \%)$ & 6 \\
Actinomyces viscosus & $7 / 331(2.1 \%)$ & 3 \\
Actinomyces meyeri & $3 / 331(0.9 \%)$ & 3 \\
Actinomyces naeslundii & $11 / 331(3.3 \%)$ & 6 \\
Actinomyces radicidentis & $2 / 331(0.6 \%)$ & 2 \\
Actinomyces species & $10 / 331(3 \%)$ & 2 \\
Actinomyces sp. I & $1 / 331(0.3 \%)$ & 1 \\
Actinomyces sp. II & $1 / 331(0.3 \%)$ & 1 \\
Actinomyces gerencseriae oral taxon 618 & $1 / 331(0.3 \%)$ & 1 \\
Actinomyces sp. oral clone CT047 & $1 / 331(0.3 \%)$ & 1 \\
Actinomyces massiliensis & $1 / 331(0.3 \%)$ & 1 \\
Actinomyces sp. oral taxon 169 clone AG004 & $3 / 331(0.9 \%)$ & 1 \\
Actinomyces sp. oral clone JA063 & $1 / 331(0.3 \%)$ & 1 \\
Actinomyces sp. oral taxon 181 strain Hal1065 & $1 / 331(0.3 \%)$ & 1 \\
Actinomyces strain B27SC & $2 / 331(0.6 \%)$ & 1 \\
Actinomyces strain C29KA & $1 / 331(0.3 \%)$ & 3 \\
Actinomyces odontolyticus & $5 / 331(1.5 \%)$ & \\
\hline
\end{tabular}

\subsection{Risk of Bias}

The risk of bias was assessed using the Newcastle-Ottawa case-control scale, modified by the authors to adapt it to microbiological studies, as already done in previous systematic reviews with meta-analyses [26,27]. The results are reported in detail in Table 7 . For each category, a value of one to three was assigned ( where one $=$ low and three $=$ high). 
Table 7. Assessment of the risk of bias within the studies (Newcastle-Ottawa scale), with scores 7 to $12=$ low quality, 13 to $20=$ intermediate quality, and 21 to $24=$ high quality.

\begin{tabular}{|c|c|c|c|c|c|c|c|c|c|c|}
\hline & & Selection & & & Comparability & & Exposure & & Score & Sub-Group \\
\hline Reference & $\begin{array}{c}\text { Definition } \\
\text { of Cases }\end{array}$ & $\begin{array}{l}\text { Representativeness } \\
\text { of Cases }\end{array}$ & $\begin{array}{c}\text { Selection } \\
\text { of Controls }\end{array}$ & $\begin{array}{l}\text { Definition } \\
\text { of Controls }\end{array}$ & $\begin{array}{l}\text { Comparability of } \\
\text { Cases and Controls } \\
\text { on the Basis of the } \\
\text { Design or Analysis }\end{array}$ & $\begin{array}{l}\text { Ascertainment } \\
\text { of Exposure }\end{array}$ & $\begin{array}{l}\text { Same Method of } \\
\text { Ascertainment } \\
\text { for Cases and } \\
\text { Controls }\end{array}$ & $\begin{array}{c}\text { Non-Response } \\
\text { Rate }\end{array}$ & & \\
\hline $\begin{array}{c}\text { [34] Ledezma-Rasillo et al., } \\
2010 \text { The Journal of clinical } \\
\text { pediatric dentistry }\end{array}$ & 3 & 1 & 2 & 2 & 2 & 2 & 3 & 0 & 15 & Streptococcus, Propionibacterium, \\
\hline $\begin{array}{l}\text { [37] Niazi et al,, } 2010 \\
\text { Journal of endodontics }\end{array}$ & 3 & 1 & 3 & 3 & 2 & 1 & 3 & 0 & 16 & $\begin{array}{c}\text { Streptococcus, Propionibacterium, } \\
\text { Peptostreptococcus, } \\
\text { Staphylococcus, Eubacterium }\end{array}$ \\
\hline $\begin{array}{l}\text { [38] Fujii et al., } 2009 \text { Oral } \\
\text { microbiology and immunology }\end{array}$ & 2 & 2 & 1 & 1 & 1 & 2 & 2 & 0 & 11 & $\begin{array}{c}\text { Streptococcus, Propionibacterium, } \\
\text { Peptostreptococcus, } \\
\text { Staphylococcus }\end{array}$ \\
\hline $\begin{array}{c}\text { [33] Siqueira et al., } 2004 \\
\text { Oral surgery, oral medicine, } \\
\text { oral pathology, oral radiology, } \\
\text { and endodontics }\end{array}$ & 3 & 1 & 1 & 1 & 1 & 3 & 2 & 0 & 12 & $\begin{array}{c}\text { Streptococcus, Propionibacterium, } \\
\text { Peptostreptococcus }\end{array}$ \\
\hline $\begin{array}{c}\text { [14] Pinheiro et al., } 2003 \\
\text { International endodontic } \\
\text { journal }\end{array}$ & 2 & 2 & 2 & 2 & 3 & 3 & 3 & 0 & 17 & $\begin{array}{c}\text { Streptococcus, Propionibacterium, } \\
\text { Peptostreptococcus, } \\
\text { Staphylococcus, Eubacterium }\end{array}$ \\
\hline $\begin{array}{l}\text { [32] Sunde et al., } 2002 \\
\text { Journal of endodontics }\end{array}$ & 2 & 2 & 2 & 2 & 3 & 2 & 3 & 0 & 16 & $\begin{array}{c}\text { Streptococcus, Propionibacterium, } \\
\text { Peptostreptococcus, } \\
\text { Staphylococcus }\end{array}$ \\
\hline $\begin{array}{l}\text { [3] Sjogren et al., } 1997 \\
\text { International endodontic } \\
\text { journal }\end{array}$ & 2 & 2 & 2 & 2 & 3 & 2 & 3 & 0 & 16 & $\begin{array}{l}\text { Streptococcus, Propionibacterium, } \\
\text { Peptostreptococcus, Eubacterium }\end{array}$ \\
\hline $\begin{array}{c}\text { [40] Debelian, et al. } 1995 \\
\text { Endodontics \& dental } \\
\text { traumatology }\end{array}$ & 2 & 2 & 2 & 2 & 3 & 2 & 2 & 0 & 15 & $\begin{array}{c}\text { Streptococcus, Propionibacterium, } \\
\text { Eubacterium }\end{array}$ \\
\hline $\begin{array}{l}\text { [39] Fukushima et al., } 1990 \\
\text { Journal of endodontics }\end{array}$ & 2 & 1 & 2 & 1 & 1 & 1 & 2 & 0 & 10 & $\begin{array}{l}\text { Streptococcus, Propionibacterium, } \\
\text { Peptostreptococcus, Eubacterium }\end{array}$ \\
\hline $\begin{array}{l}\text { [35] Sundqvist et al., } 1989 \\
\text { Journal of endodontics }\end{array}$ & 3 & 3 & 3 & 1 & 1 & 1 & 2 & 0 & 14 & $\begin{array}{c}\text { Streptococcus, Peptostreptococcus, } \\
\text { Eubacterium }\end{array}$ \\
\hline $\begin{array}{l}\text { [36] Abou-Rass et al., } 1998 \\
\text { International endodontic } \\
\text { journal }\end{array}$ & 2 & 2 & 2 & 2 & 2 & 2 & 2 & 0 & 14 & $\begin{array}{c}\text { Streptococcus, Propionibacterium, } \\
\text { Peptostreptococcus, } \\
\text { Staphylococcus }\end{array}$ \\
\hline
\end{tabular}


Studies presenting a high risk of bias were not included in the meta-analysis. Articles with a high bias risk were excluded from the scale and eliminated during the inclusion phase. Other articles were excluded because for the outcomes investigated; they presented the same data and samples.

The bias risk assessment of the 11 articles included was conducted by the first reviewer (M.D.).

The risk of bias between the studies was considered low for five sub-groups of the primary research outcome; in fact, the heterogeneity that emerges from the meta-analysis shows an $I^{2}$ equal to $54 \%$ for sub-group 2 (Propionibacterium), $44 \%$ for sub-group 3 (Peptostreptococcus), 30\% for sub-group 4 (Staphylococcus) and 0\% for sub-groups 1 and 2 (Streptococcus, Eubacterium). The low heterogeneity is also confirmed by the funnel plot (Figures 2-6).

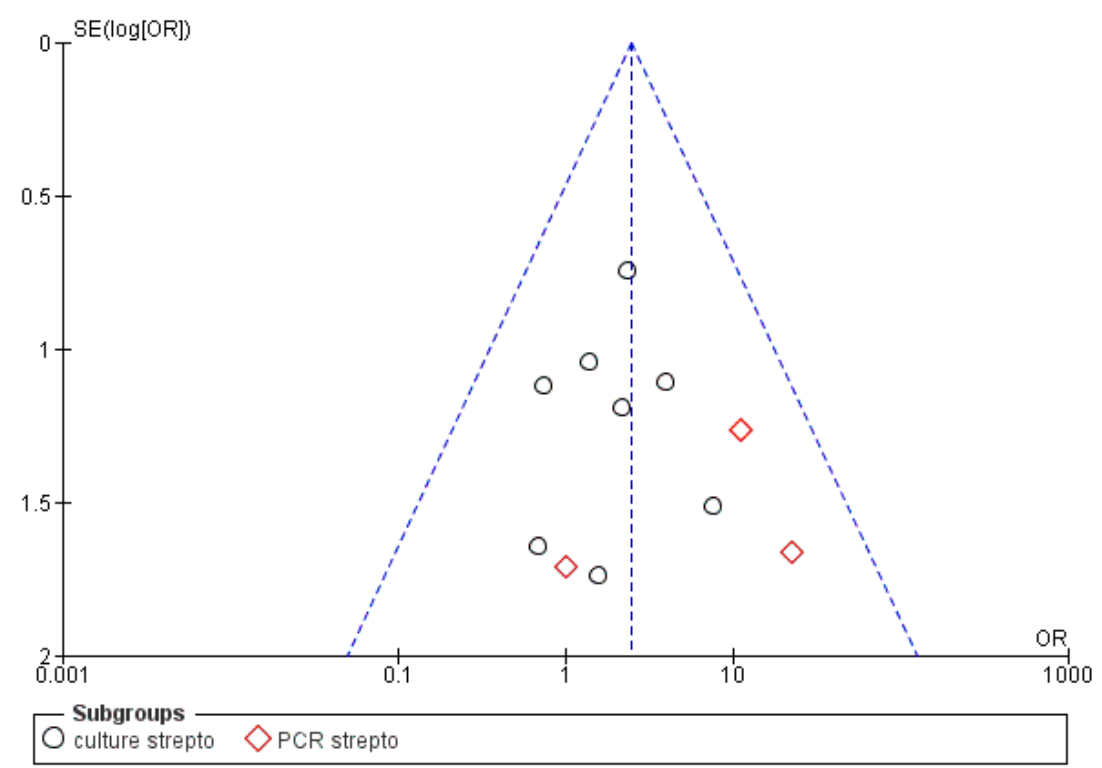

Figure 2. Funnel plot for the sub-group Streptococcus, $I^{2}=0 \%$. The absence of heterogeneity is evident graphically. Sub-group culture $I^{2}=0 \%$. Sub-group PCR $I^{2}=0 \%$. The heterogeneity between the two sub-groups is $I^{2}=58.2 \%$. OR: odds ratio, SE: standard error.

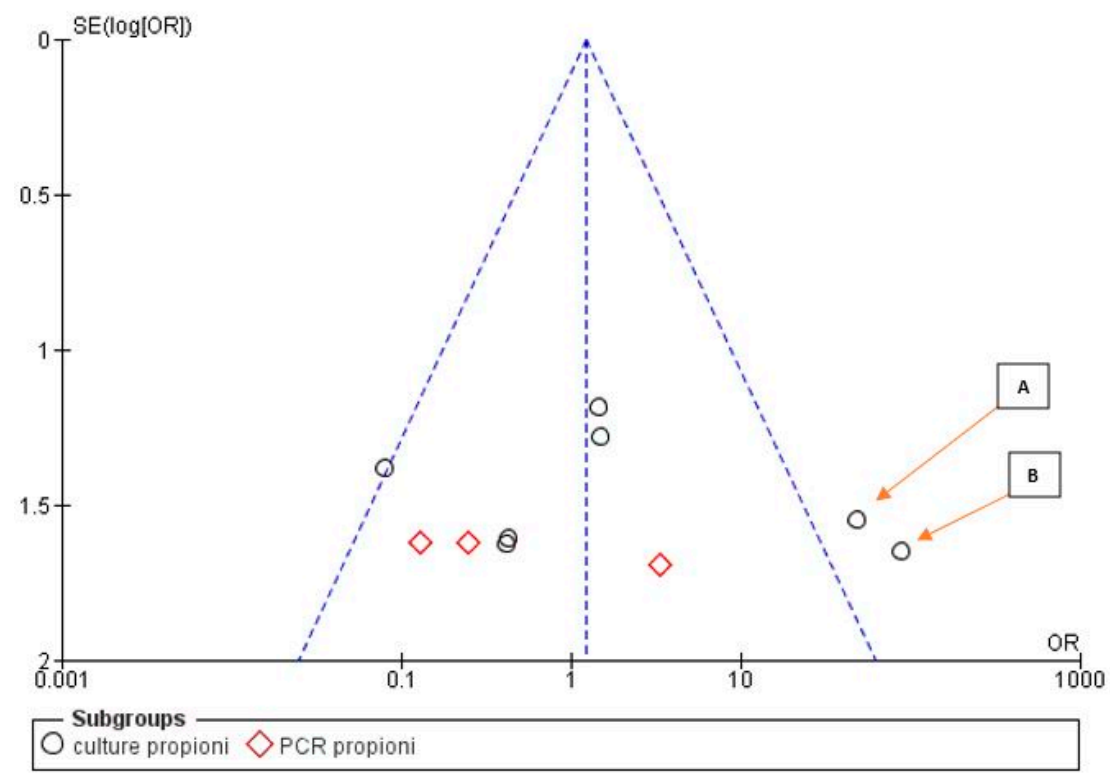

Figure 3. Funnel plot for the sub-group Propionibacterium, $I^{2}=56 \%$. The presence of heterogeneity is highlighted graphically. The arrows highlight the sources of heterogeneity A: Fukushima, 1990; B: Sunde, 2002. Sub-group culture $I^{2}=64 \%$. Sub-group PCR $I^{2}=5 \%$. The heterogeneity between the two sub-groups is $I^{2}=13 \%$. 


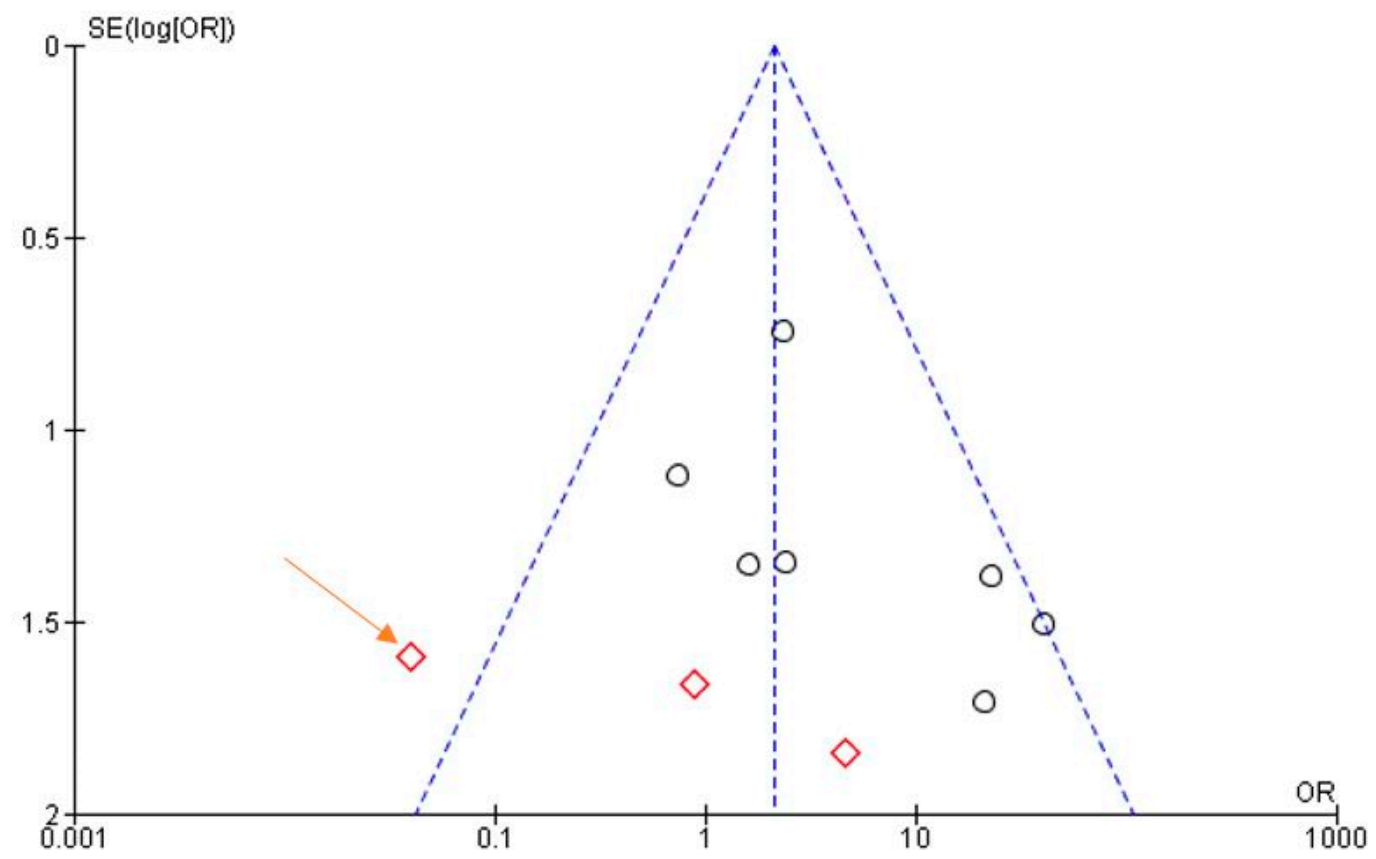

- Subgroups

$\bigcirc$ culture peptostre $\quad \triangle P C R$ peptostre

Figure 4. Funnel plot for the sub-group Peptostreptococcus, $I^{2}=44 \%$. Sub-group culture $I^{2}=27 \%$. Sub-group PCR $I^{2}=53 \%$. The heterogeneity between the two sub-groups is $I^{2}=86.9 \%$. The arrow indicates that the study of Niazi, 2010 is the likely source of heterogeneity.

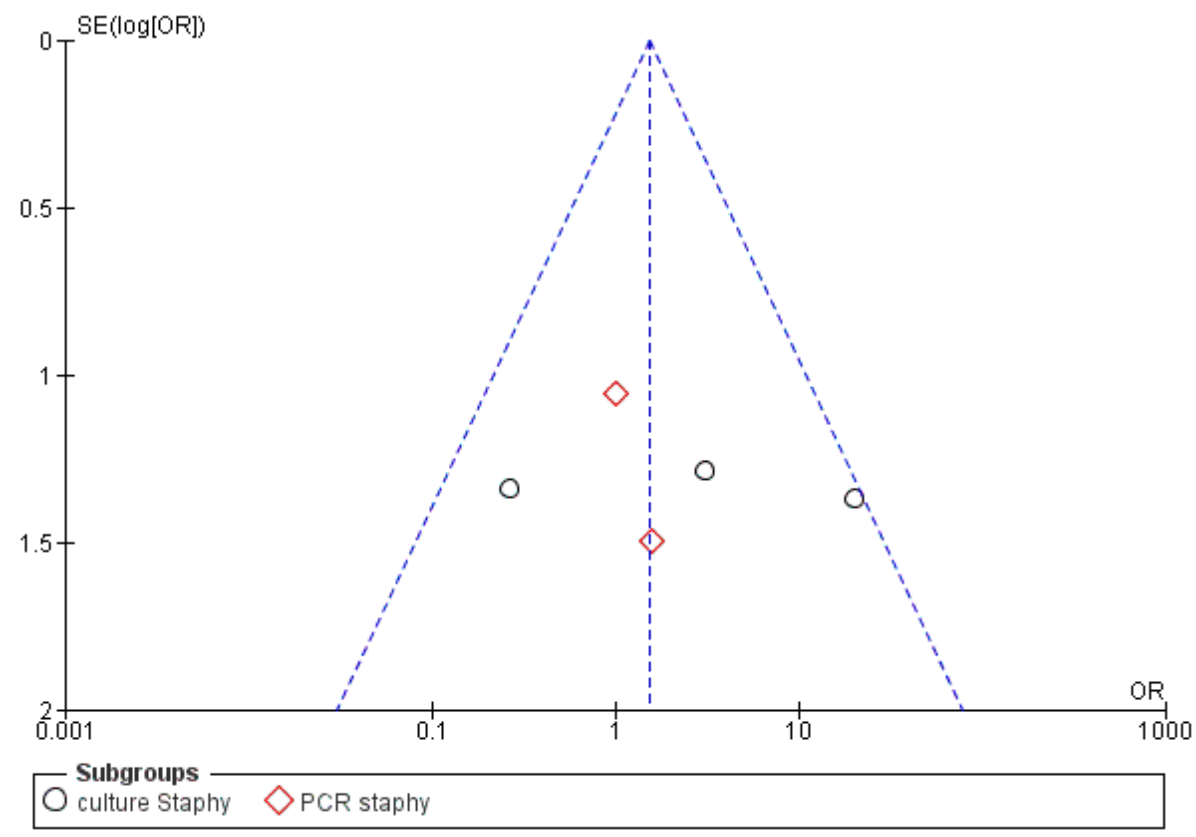

Figure 5. Funnel plot for the sub-group Staphylococcus, $I^{2}=30 \%$. Sub-group culture $I^{2}=62 \%$. Sub-group PCR $I^{2}=0 \%$. The heterogeneity between the two sub-groups is $I^{2}=0 \%$. 


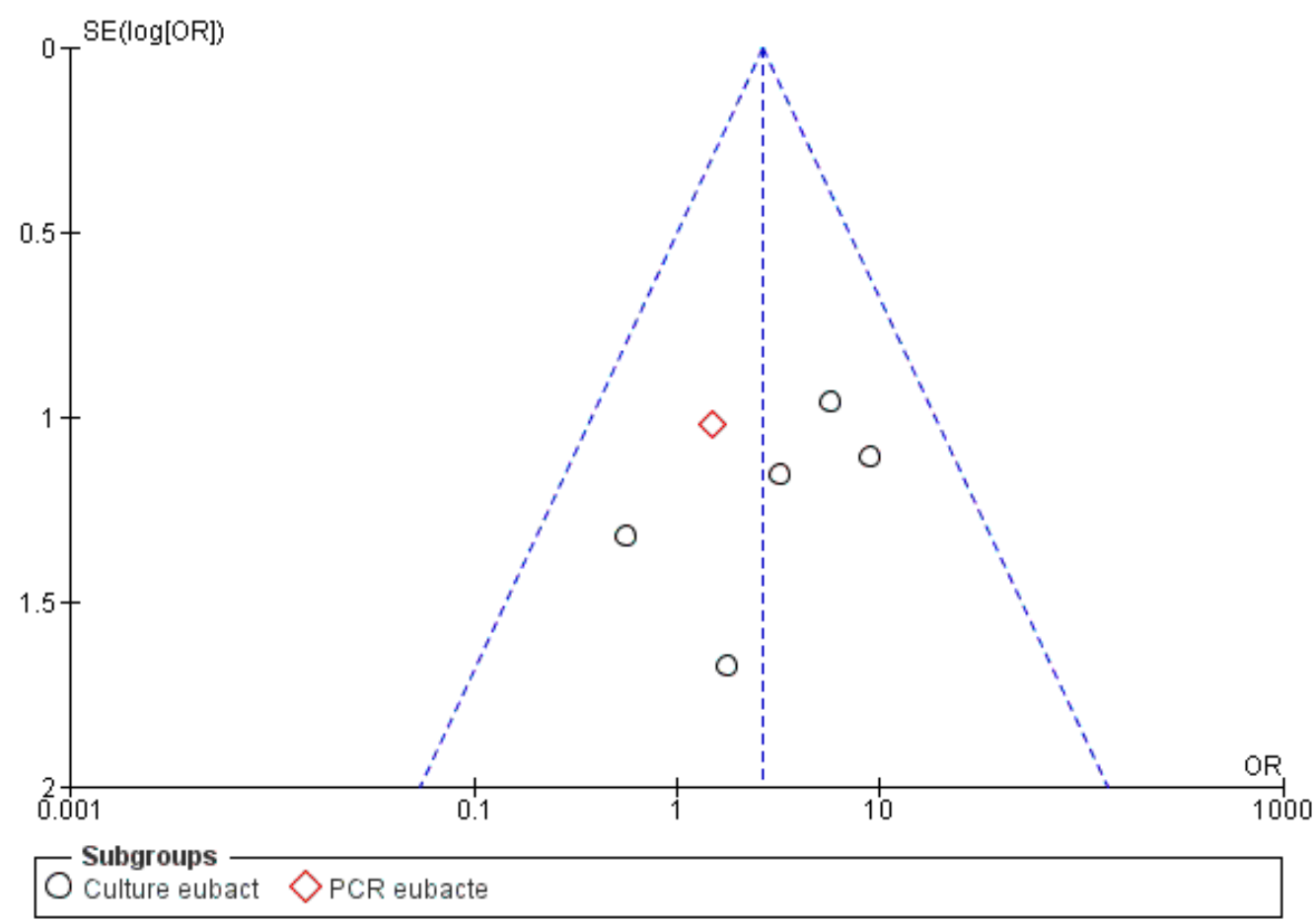

Figure 6. Funnel plot for the sub-group Eubacterium, $I^{2}=0 \%$. Sub-group culture $I^{2}=0 \%$. The heterogeneity between the two sub-groups is $I^{2}=0 \%$.

For the second sub-group, graphical analysis of the funnel plot indicates the studies of Fukushima et al. 1990 [39] and Sunde et al. 2002 [32] as possible sources of heterogeneity and bias.

Graphic evaluation of the confidence intervals for the individual studies (forest plot) shows a good overlap for the Streptococci and Eubacterium sub-groups, and poor overlap for the Propionibacterium group, confirming the lack of heterogeneity in the Streptococci and Eubacterium sub-groups, and the high heterogeneity for Propionibacterium (Cochrane Handbook for Systematic Reviews of Interventions, chapter 9.5.2, identifying and measuring heterogeneity). Since heterogeneity is a sign of a possible risk of bias between the studies, it was decided to investigate meta-regression as a function of the risk of bias determined for each individual studies.

\subsection{Meta-Analysis}

The statistical analysis of the data was performed using the Rev-manager 5.4 software (Copenhagen, 153 Denmark, The Nordic Cochrane Centre, The Nordic Cochrane Collaboration, 2014).

The meta-analysis of the first sub-group (Streptococci) showed an absence of heterogeneity with $I^{2}$ equal to $0 \%$, and a fixed effects model was applied. The results shown in Figure 7 show that Streptococci are more likely to occur in samples with Actinomyces (OR $=2.49 ; 95 \%$ confidence interval (CI): [1.27, 4.86]).

The meta-analysis of the second sub-group (Propionibacterium) showed high heterogeneity, with $I^{2}$ equal to $56 \%$, and a random effects model was applied. The results shown in Figure 8 show that Propionibacterium are not more likely to occur in samples with Actinomyces (OR $=1.26,95 \% \mathrm{CI}$ : $[0.31,5.13])$. 


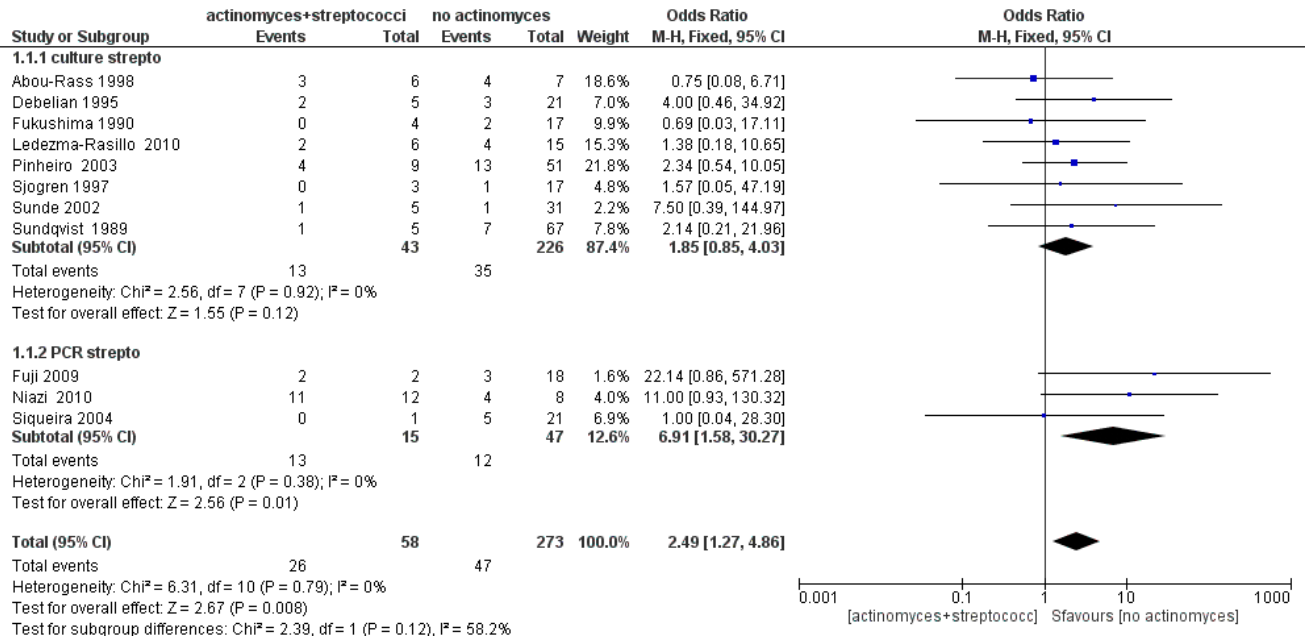

Figure 7. Forest plot of the fixed effects model of the meta-analysis of the sub-group Streptococci. Sub-group culture (OR = 1.85, 95\% confidence interval $(\mathrm{CI}):[0.27,4.03])$, sub-group PCR (OR = 6.91, 95\% CI: [1.58, 30.27]).

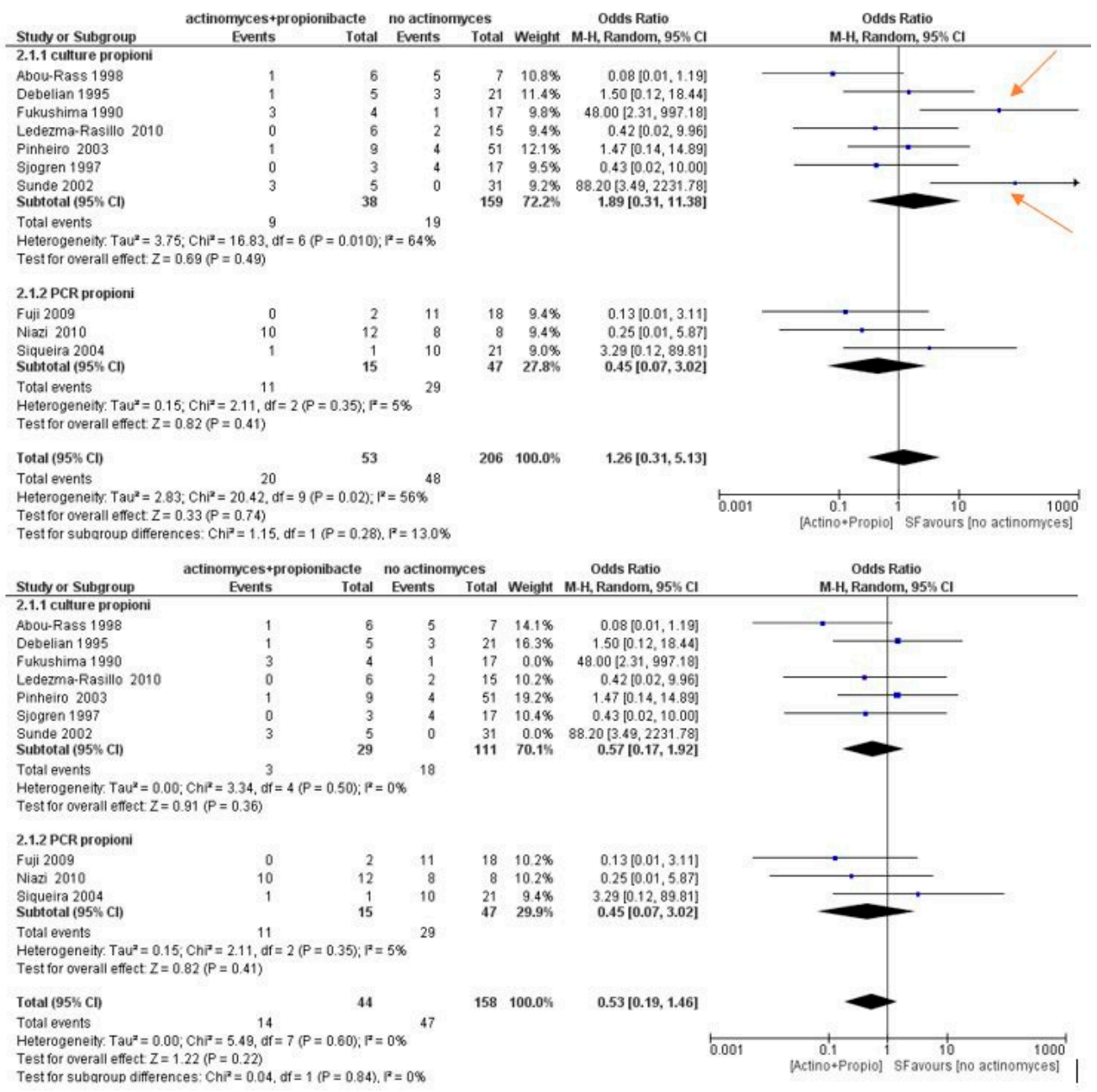

Figure 8. Forest plot of the random effects model of the meta-analysis of the sub-group Propionibacterium; the arrows indicate the sources of heterogeneity that are identified by the funnel plot and are also evident on the forest plot. Sub-group culture (OR = 1.89, 95\% CI: [0.31, 11.38]), sub-group PCR (OR $=0.45,95 \%$ CI: $[0.07,3.02])$. 
With the identification and elimination of the two sources of heterogeneity, it is evident that $I^{2}$ drops to values equal to $0 \%$; despite the elimination of the two studies, the forest plot does not report data with statistically insignificant odds ratios in favor of the samples with Actinomyces.

Furthermore, a meta-regression was conducted as a function of the risk of bias evaluation within the studies, in order to investigate whether the risk of bias within the studies could be a source of heterogeneity and bias between the studies. From the statistical analysis, we find a regression coefficient equal to -0.140 , with a $p$ value 0.639 (Table 8 ). The meta-regression data are not statistically significant, and the high heterogeneity index does not depend on the bias in the studies (Figure 9).

Table 8. Random effects model: regression results for the risk of bias.

\begin{tabular}{ccccccc}
\hline Covariate & Coefficients & Lower Bound & Upper Bound & Std. Error & Z-Value & $p$-Value \\
\hline Intercept & 2.226 & -6.222 & 10.675 & 4.310 & 0.5164 & 0.605 \\
\hline Risk of bias & -0.140 & -0.724 & 0.444 & 0.298 & -0.4697 & 0.639 \\
\hline
\end{tabular}

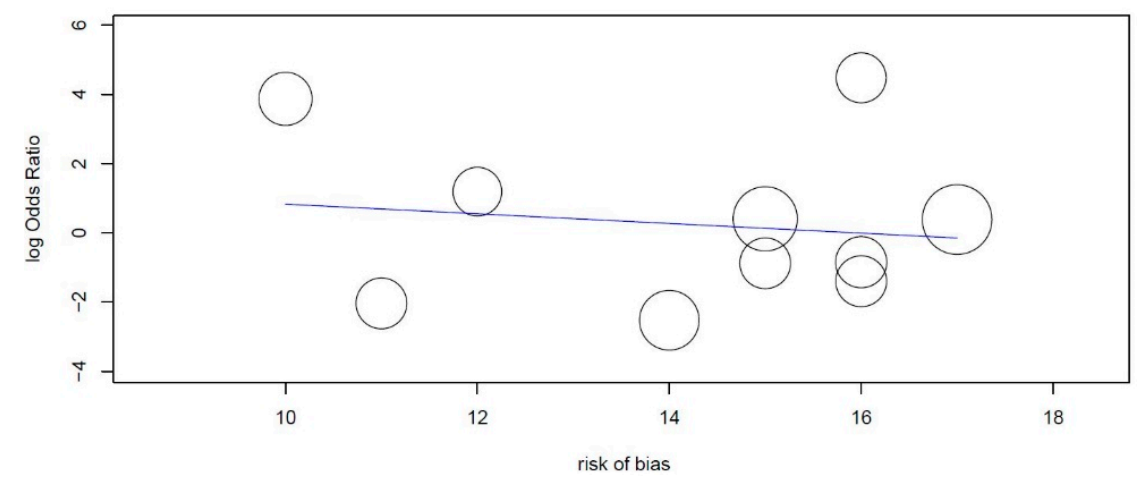

Figure 9. Meta-regression plot; it can be seen that the log odds ratio decreases when the risk of bias decreases, with a regression coefficient equal to -0.140 per score of risk of bias points, and with a $p$ value of 0.639 .

The meta-analysis of the third sub-group (Peptostreptococci) showed average heterogeneity, with $I^{2}$ equal to $44 \%$, and a fixed effects model was applied. The results shown in Figure 10 show that Peptostreptococci are more likely to occur in samples with Actinomyces (OR $=2.14,95 \%$ CI: $[1.1,4.11]$ ).

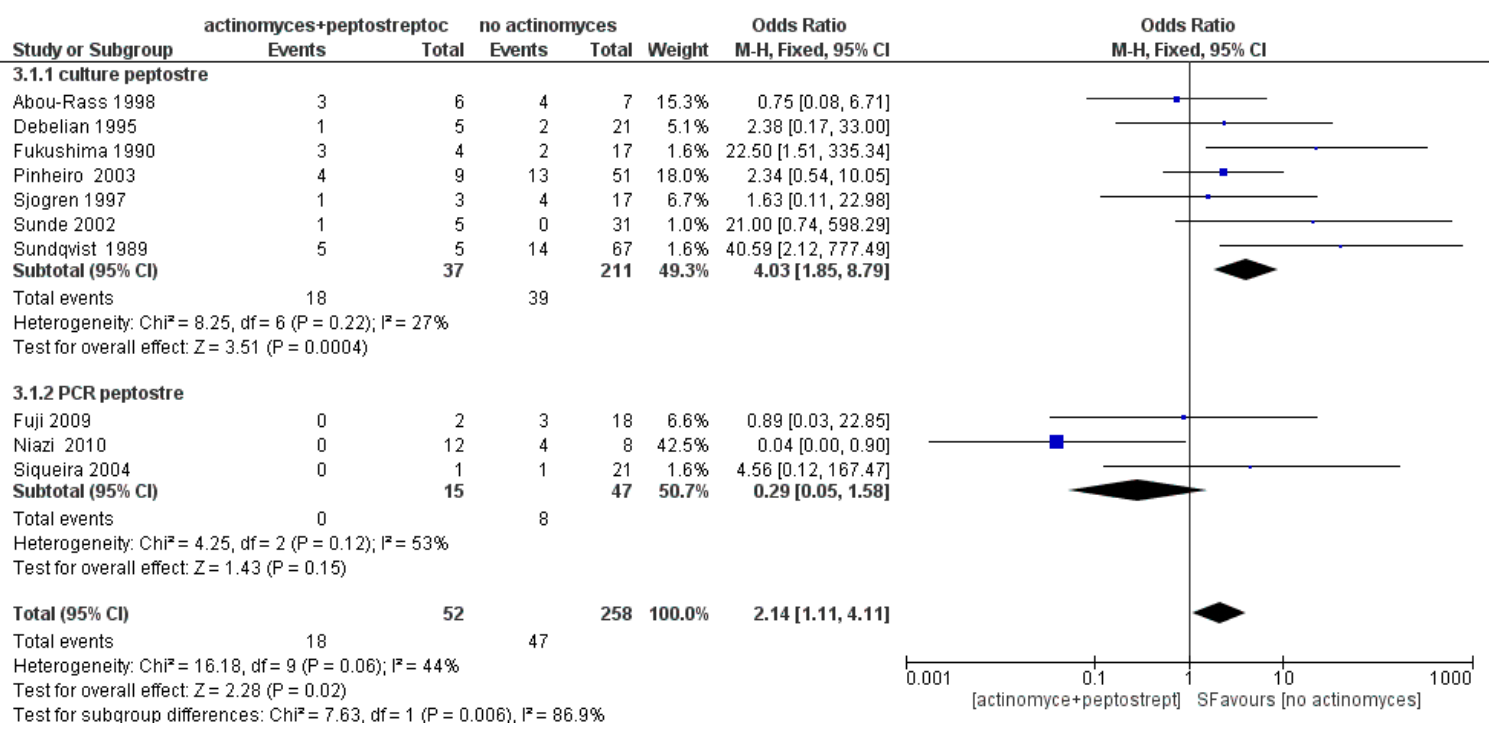

Figure 10. Forest plot of the fixed effects model of the meta-analysis of sub-group Peptostreptococci. Sub-group culture (OR = 4.03, 95\% CI: $[1.85,8.79])$, sub-group PCR (OR = 0.29, 95\% CI: [0.05, 1.58]). 
The meta-analysis of the fourth sub-group (Staphylococci) showed average heterogeneity, with $I^{2}$ equal to $30 \%$, and a fixed effects model was applied. The results shown in Figure 11 show that Staphylococci are not more likely to occur in samples with Actinomyces (OR $=1.54,95 \%$ CI: [0.54, 4.37]).

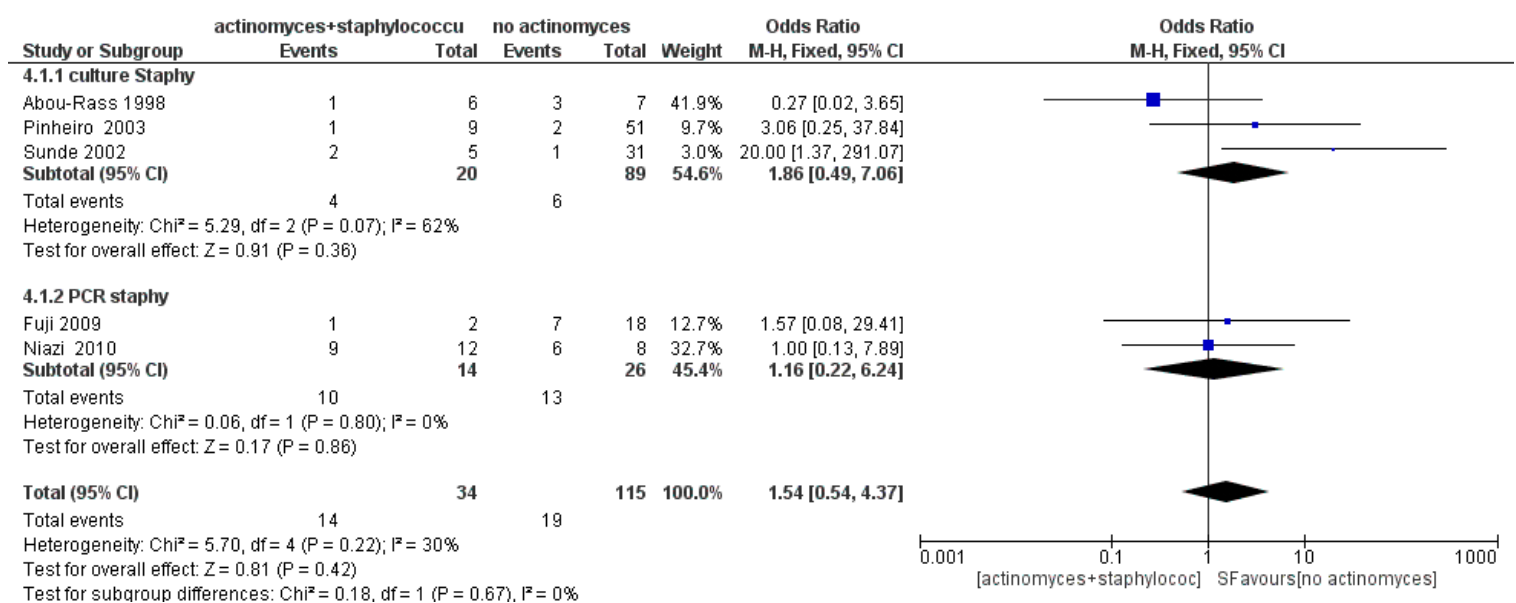

Figure 11. Forest plot of the fixed effects model of the meta-analysis of the sub-group Staphylococci.

Sub-group culture (OR $=1.86,95 \%$ CI: $[0.49,7.06]$ ), sub-group PCR (OR $=1.16,95 \%$ CI: [0.22, 6.24]).

The meta-analysis of the fifth sub-group Eubacterium showed an absence of heterogeneity, with $I^{2}$ equal to $0 \%$, and a fixed effects model was applied. The results shown in Figure 12 show that Eubacterium are more likely to occur in samples with Actinomyces (OR $=2.68,95 \%$ CI: $[1.10,6.51])$.

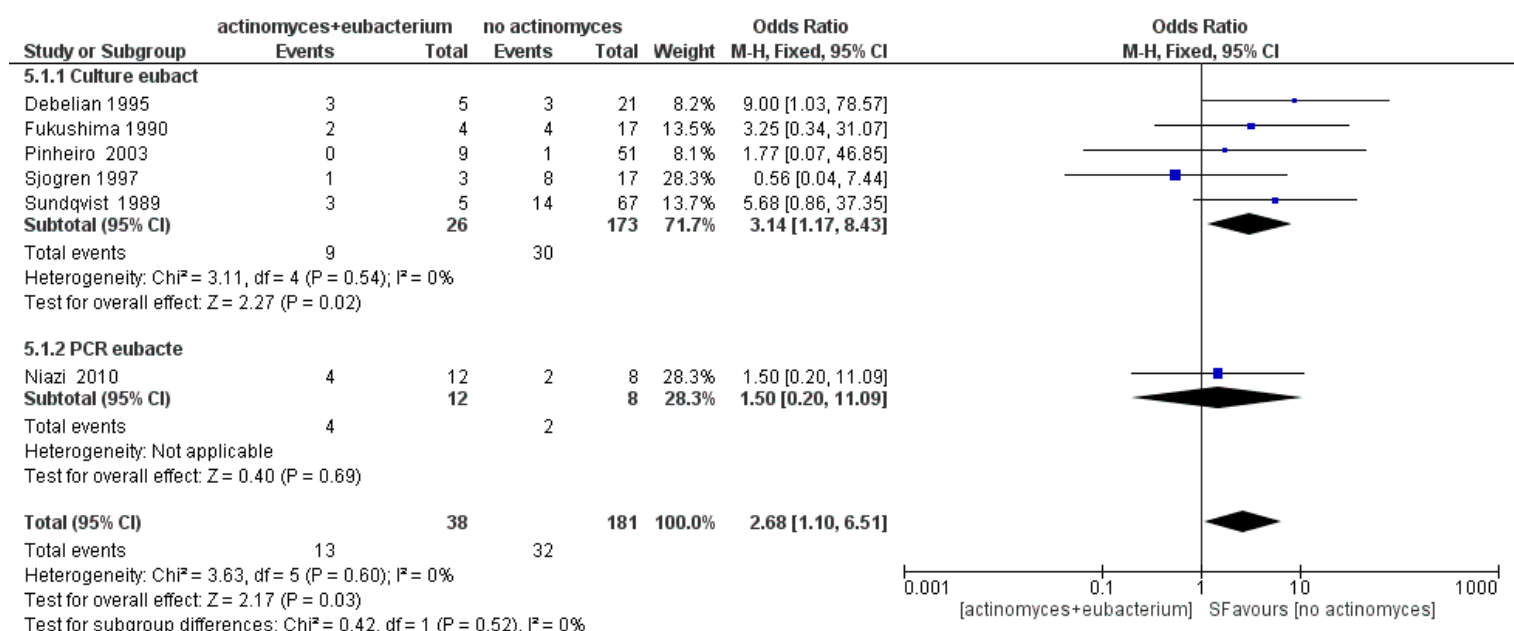

Figure 12. Forest plot of the fixed effects model of the meta-analysis of the sub-group Eubacterium. Sub-group culture (OR = 3.14, 95\% CI: $[1.17,8.43])$, sub-group PCR (OR = 1.50, 95\% CI: [0.20, 11.09]).

\section{Discussion}

Follow-up studies report success rates of around $80-90 \%$ when canals are treated endodontically in aseptic conditions $[5,41,42]$. Endodontic failures mainly manifest when procedures are used that have not fulfilled the standard conditions for the elimination of microorganisms inside the endodontic lesion. Long-term follow-ups have demonstrated the presence of endodontic failures, with the presence of apical radiolucent lesions, even on teeth apparently treated adequately with procedures that meet high standards, demonstrating the persistence of infections that affect the apical portion of the dental roots.

Factors that may contribute to the perpetuation of periapical radio transparencies after root canal treatment include the following: an intraradicular infection that persists in the apical part of the root canal [42]; an extraradicular infection, generally in the form of periapical actinomycosis [42]; the filling 
of the extruded root canal, or other materials that cause reactions to foreign bodies [43-45]; and cysts, especially those with a significant accumulation of cholesterol crystals [46,47].

The samples considered in this review are primary and secondary endodontic lesions; of the 331 analyzed samples, 46 bacterial genera were detected in association with bacteria of the genus Actinomyces, and of these, the most frequently identified were Streptococcus (26/58), Propionibacterium (20/58), Peptostreptococcus (14/58), Staphylococcus (14/58), Eubacterium (13/58), Prevotella (10/58), Veillonella (8/58), Gemella (8/58), Clostridium (7/58), Bifidobacterium (7/58), Lactobacillus (7/58) and Fusobacterium (7/58). Streptococcus is the genus most frequently identified in multiple studies (eight articles), followed by Peptostreptococcus and Propionibacterium (seven articles) and then Staphylococcus, Eubacterium, Fusobacterium and Prevotella (five articles).

Other studies in the literature have examined biofilm formation in the canal space or on the outer surface of the apical portion of the root $[13,48]$.

However, information on extraradicular infections resulting in a persistent lesion is limited, and mainly references Actinomyces or Propionibacterium species [32,33,49,50]. Bacteria that are difficult to grow are often only cultured through non-traditional methods, which leads to an underestimation of the bacterial diversity associated with persistent disease [51].

Most bacteria isolated from infected root canals are oxygen-sensitive, and cannot be grown using conventional bacteriological methods [52].

In previous studies that assessed the influence of infection on the treatment outcome, bacteriological techniques that were unfavorable for use in the recovery of anaerobic bacteria were used $[53,54]$. Therefore, the presence of bacteria that may have been important for the outcome of the treatment may have been precluded, and cases that apparently did not contain bacteria could, in fact, have hosted persistent microorganisms.

As PCR can overcome some of the intrinsic limitations of the culture process, it has contributed significantly to our understanding of the endodontic microbiota associated with primary infections [11].

The lesions analyzed in this review were both primary and secondary endodontic lesions; the bacteria were identified in the lesions by culture and PCR.

A study that identified multiple bacterial genera associated with Actinomyces was conducted by Niazi et al. (2010), who identified 35 bacterial genera in refractory endodontic lesions (9 with abscesses and 11 without abscesses) and 11 species of Actinomyces [37]. A considerable number of bacterial genera were also identified by Pinheiro et al. (2003) and Debelian et al. (1995), who identified 12 bacterial genera [14,40].

When using culture techniques, the microbes most commonly found in the endodontic canals of teeth with post-treatment endodontic disease are primarily Gram-positive, including rods (e.g., Actinomyces and Propionibacterium) and cocci (e.g., Enterococcus spp., Streptococcus spp.) [2,12,14,55].

The meta-analysis of the sub-groups of the five bacteria most commonly found in the samples with Actinomyces highlighted how the bacteria of the genera Streptococci, Peptostreptococci and Eubacterium are more likely to be found in samples positive for Actinomyces, compared to the negative samples, with odds ratios of 2.49, 2.14 and 2.68, respectively. The meta-analysis of the Propionibacterium and Staphylococci sub-groups indicated how testing positive for these two genera of bacteria is found with the same propensity in samples that are positive, as those which are negative, for "Actinomyces".

For all the other bacteria, there are no indications from this meta-analysis suggesting their greater frequency in primary and secondary lesions with Actinomyces; in fact, the literature review shows us that many bacteria are more frequently found in endodontic lesions than in Actinomyces.

Bacteria of the genus Actinomyces are constantly being reclassified with the identification of new bacterial species. Bacteria that are present in the oral cavity, and that can potentially cause secondary or persistent infections, are commonly found in the gastroenteric system or in the mucous membranes of the urogenital tract $[56,57]$.

The species of Actinomyces most involved in endodontic lesions are $A$. israelii (15/331), A. naeslundii (11/331), A. species (10/331), A. viscosus (7/331) and A. odontolyticus (5/331). A. israelii and A. naeslundii 
were identified in six different articles, $A$. viscosus, A. meyeri and A. odontolyticus were reported in three articles, and $A$. radicidentis were identified in two articles. The remaining species were identified in different individual studies.

A group of these bacteria has been shown to cause actinomycosis, progressing chronically as diseases manifesting abscesses associated with tissue fibrosis and draining sinuses, and sometimes mimicking malignant tumors [58-60].

Actinomyces israelii is the most commonly isolated species in human actinomycosis [61,62]. The loss of the integrity of the mucous membrane of the oral cavity, caused by extractions, bone and dental fractures, anesthesia, periodontal disease and the endodontic treatment of pulp exposures, can give rise to infection by these microorganisms, which, upon the interruption of the continuity of oral tissue, infect and invade the underlying tissues, thanks also to the selective conditions of anaerobiosis [63-65].

The limits of the study are the heterogeneity of the outcomes sought from the clinical studies included in the meta-analysis, sometimes with different microbiological identification methods, and the continuously updated taxonomy of bacterial species. The data are therefore to be considered as an indication (with an analytical basis) of which might be main bacteria associated with Actinomyces, which we consider to be one of the main culprits of perpetrators intraradicular and extraradicular infections.

\section{Conclusions}

Bacteria of the genera Streptococcus and Propionibacterium are those that are most frequently associated with Actinomyces in the considered endodontic lesions, and Actinomyces israelii is the most frequently involved species.

The microorganisms found in endodontic failures remain in the root canal after previous treatment, or enter during or after treatment through a leak. For all the other bacteria, the literature review shows us that many bacteria are more frequently found in endodontic lesions than in Actinomyces. therefore, thorough knowledge and a deep understanding of these endodontic microbes can assist in making decisions for further surgical treatment or reprocessing.

Author Contributions: Conceptualization, M.D., V.C., R.C., F.A., R.A., E.L., A.D.L. and M.A.; methodology, M.D. and D.S.; software, G.T.; validation, M.D.; formal analysis, M.D. and C.Q.; investigation, D.S. and C.Q.; resources, L.L.M.; data curation; writing - original draft preparation, M.D., C.Q., and G.T.; writing—review and editing, M.D., G.T., C.Q., and L.L.M. All authors have read and agreed to the published version of the manuscript.

Funding: This research received no external funding.

Acknowledgments: All the acknowledgments go to Lorenzo Lo Muzio, Director of the Dental Clinic and President of the Department of Clinical and Experimental Medicine of the University of Foggia, who gave fundamental technical support in the writing of this article.

Conflicts of Interest: The authors declare no conflict of interest.

\section{References}

1. Cheung, G.S.; Ho, M.W. Microbial flora of root canal-treated teeth associated with asymptomatic periapical radiolucent lesions. Oral Microbiol. Immunol. 2001, 16, 332-337. [CrossRef]

2. Sundqvist, G.; Figdor, D.; Persson, S.; Sjogren, U. Microbiologic analysis of teeth with failed endodontic treatment and the outcome of conservative re-treatment. Oral Surg. Oral Med. Oral Pathol. Oral Radiol. Endod. 1998, 85, 86-93. [CrossRef]

3. Sjogren, U.; Figdor, D.; Persson, S.; Sundqvist, G. Influence of infection at the time of root filling on the outcome of endodontic treatment of teeth with apical periodontitis. Int. Endod. J. 1997, 30, 297-306. [CrossRef]

4. Siqueira, J.F., Jr.; Rocas, I.N. Clinical implications and microbiology of bacterial persistence after treatment procedures. J. Endod. 2008, 34, 1291-1301.e3. [CrossRef]

5. Kerekes, K.; Tronstad, L. Long-term results of endodontic treatment performed with a standardized technique. J. Endod. 1979, 5, 83-90. [CrossRef]

6. Narayanan, L.L.; Vaishnavi, C. Endodontic microbiology. J. Conserv. Dent. 2010, 13, 233-239. [CrossRef] 
7. Torabinejad, M.; Ung, B.; Kettering, J.D. In vitro bacterial penetration of coronally unsealed endodontically treated teeth. J. Endod. 1990, 16, 566-569. [CrossRef]

8. Tronstad, L.; Kreshtool, D.; Barnett, F. Microbiological monitoring and results of treatment of extraradicular endodontic infection. Endod. Dent. Traumatol. 1990, 6, 129-136. [CrossRef]

9. Nair, P.N. On the causes of persistent apical periodontitis: A review. Int. Endod. J. 2006, 39, $249-281$. [CrossRef]

10. Siqueira, J.F., Jr. Aetiology of root canal treatment failure: Why well-treated teeth can fail. Int. Endod. J. 2001, 34, 1-10. [CrossRef]

11. Siqueira, J.F., Jr. Endodontic infections: Concepts, paradigms, and perspectives. Oral Surg. Oral Med. Oral Pathol. Oral Radiol. Endod. 2002, 94, 281-293. [CrossRef] [PubMed]

12. Molander, A.; Reit, C.; Dahlen, G.; Kvist, T. Microbiological status of root-filled teeth with apical periodontitis. Int. Endod. J. 1998, 31, 1-7. [CrossRef] [PubMed]

13. Wang, J.; Jiang, Y.; Chen, W.; Zhu, C.; Liang, J. Bacterial flora and extraradicular biofilm associated with the apical segment of teeth with post-treatment apical periodontitis. J. Endod. 2012, 38, 954-959. [CrossRef]

14. Pinheiro, E.T.; Gomes, B.P.; Ferraz, C.C.; Sousa, E.L.; Teixeira, F.B.; Souza-Filho, F.J. Microorganisms from canals of root-filled teeth with periapical lesions. Int. Endod. J. 2003, 36, 1-11. [CrossRef] [PubMed]

15. Stuart, C.H.; Schwartz, S.A.; Beeson, T.J.; Owatz, C.B. Enterococcus faecalis: Its role in root canal treatment failure and current concepts in retreatment. J. Endod. 2006, 32, 93-98. [CrossRef] [PubMed]

16. Zhu, X.; Wang, Q.; Zhang, C.; Cheung, G.S.; Shen, Y. Prevalence, phenotype, and genotype of Enterococcus faecalis isolated from saliva and root canals in patients with persistent apical periodontitis. J. Endod. 2010, 36, 1950-1955. [CrossRef]

17. Ates, M.; Akdeniz, B.G.; Sen, B.H. The effect of calcium chelating or binding agents on Candida albicans. Oral Surg. Oral Med. Oral Pathol. Oral Radiol. Endod. 2005, 100, 626-630. [CrossRef]

18. Tong, Z.; Ling, J.; Lin, Z.; Li, X.; Mu, Y. The effect of MTADN on 10 Enterococcus faecalis isolates and biofilm: An in vitro study. J. Endod. 2013, 39, 674-678. [CrossRef]

19. Kolenbrander, P.E. Oral microbial communities: Biofilms, interactions, and genetic systems. Annu. Rev. Microbiol. 2000, 54, 413-437. [CrossRef]

20. Chavez de Paz, L.E. Redefining the persistent infection in root canals: Possible role of biofilm communities. J. Endod. 2007, 33, 652-662. [CrossRef]

21. Gomes, B.P.; Pinheiro, E.T.; Sousa, E.L.; Jacinto, R.C.; Zaia, A.A.; Ferraz, C.C.; de Souza-Filho, F.J. Enterococcus faecalis in dental root canals detected by culture and by polymerase chain reaction analysis. Oral Surg. Oral Med. Oral Pathol. Oral Radiol. Endod. 2006, 102, 247-253. [CrossRef] [PubMed]

22. Rolph, H.J.; Lennon, A.; Riggio, M.P.; Saunders, W.P.; MacKenzie, D.; Coldero, L.; Bagg, J. Molecular identification of microorganisms from endodontic infections. J. Clin. Microbiol. 2001, 39, 3282-3289. [CrossRef] [PubMed]

23. Downes, J.; Munson, M.A.; Spratt, D.A.; Kononen, E.; Tarkka, E.; Jousimies-Somer, H.; Wade, W.G. Characterisation of Eubacterium-like strains isolated from oral infections. J. Med. Microbiol. 2001, 50, 947-951. [CrossRef] [PubMed]

24. Relman, D.A. Emerging infections and newly-recognised pathogens. Neth. J. Med. 1997, 50, 216-220. [CrossRef]

25. Moher, D.; Liberati, A.; Tetzlaff, J.; Altman, D.G.; Group, P. Preferred reporting items for systematic reviews and meta-analyses: The PRISMA statement. PLoS Med. 2009, 6, e1000097. [CrossRef] [PubMed]

26. Dioguardi, M.; Alovisi, M.; Crincoli, V.; Aiuto, R.; Malagnino, G.; Quarta, C.; Laneve, E.; Sovereto, D.; Lo Russo, L.; Troiano, G.; et al. Prevalence of the Genus Propionibacterium in Primary and Persistent Endodontic Lesions: A Systematic Review. J. Clin. Med. 2020, 9, 739. [CrossRef] [PubMed]

27. Dioguardi, M.; Crincoli, V.; Laino, L.; Alovisi, M.; Sovereto, D.; Lo Muzio, L.; Troiano, G. Prevalence of Bacteria of Genus Actinomyces in Persistent Extraradicular Lesions-Systematic Review. J. Clin. Med. 2020, 9, 457. [CrossRef]

28. Dioguardi, M.; Crincoli, V.; Laino, L.; Alovisi, M.; Sovereto, D.; Mastrangelo, F.; Russo, L.L.; Muzio, L.L. The Role of Periodontitis and Periodontal Bacteria in the Onset and Progression of Alzheimer's Disease: A Systematic Review. J. Clin. Med. 2020, 9, 495. [CrossRef]

29. Skerman, V.B.D.; McGowan, V.; Sneath, P.H.A. Approved lists of bacterial names. Med. J. Aust. 1980, $2,3-4$. [CrossRef] 
30. Lo, C.K.; Mertz, D.; Loeb, M. Newcastle-Ottawa Scale: Comparing reviewers' to authors' assessments. BMC Med. Res. Methodol. 2014, 14, 45. [CrossRef]

31. Stang, A. Critical evaluation of the Newcastle-Ottawa scale for the assessment of the quality of nonrandomized studies in meta-analyses. Eur. J. Epidemiol. 2010, 25, 603-605. [CrossRef] [PubMed]

32. Sunde, P.T.; Olsen, I.; Debelian, G.J.; Tronstad, L. Microbiota of periapical lesions refractory to endodontic therapy. J. Endod. 2002, 28, 304-310. [CrossRef]

33. Siqueira, J.F., Jr.; Rocas, I.N. Polymerase chain reaction-based analysis of microorganisms associated with failed endodontic treatment. Oral Surg. Oral Med. Oral Pathol. Oral Radiol. Endod. 2004, 97, 85-94. [CrossRef]

34. Ledezma-Rasillo, G.; Flores-Reyes, H.; Gonzalez-Amaro, A.M.; Garrocho-Rangel, A.; Ruiz-Rodriguez Mdel, S.; Pozos-Guillen, A.J. Identification of cultivable microorganisms from primary teeth with necrotic pulps. J. Clin. Pediatr. Dent. 2010, 34, 329-333. [CrossRef] [PubMed]

35. Sundqvist, G.; Johansson, E.; Sjogren, U. Prevalence of black-pigmented bacteroides species in root canal infections. J. Endod. 1989, 15, 13-19. [CrossRef]

36. Abou-Rass, M.; Bogen, G. Microorganisms in closed periapical lesions. Int. Endod. J. 1998, 31, 39-47. [CrossRef]

37. Niazi, S.A.; Clarke, D.; Do, T.; Gilbert, S.C.; Mannocci, F.; Beighton, D. Propionibacterium acnes and Staphylococcus epidermidis isolated from refractory endodontic lesions are opportunistic pathogens. J. Clin. Microbiol. 2010, 48, 3859-3869. [CrossRef]

38. Fujii, R.; Saito, Y.; Tokura, Y.; Nakagawa, K.I.; Okuda, K.; Ishihara, K. Characterization of bacterial flora in persistent apical periodontitis lesions. Oral Microbiol. Immunol. 2009, 24, 502-505. [CrossRef]

39. Fukushima, H.; Yamamoto, K.; Hirohata, K.; Sagawa, H.; Leung, K.P.; Walker, C.B. Localization and identification of root canal bacteria in clinically asymptomatic periapical pathosis. J. Endod. 1990, 16, 534-538. [CrossRef]

40. Debelian, G.J.; Olsen, I.; Tronstad, L. Bacteremia in conjunction with endodontic therapy. Endod. Dent. Traumatol. 1995, 11, 142-149. [CrossRef]

41. Molven, O.; Halse, A. Success rates for gutta-percha and Kloroperka N-0 root fillings made by undergraduate students: Radiographic findings after 10-17 years. Int. Endod. J. 1988, 21, 243-250. [CrossRef] [PubMed]

42. Sjogren, U.; Happonen, R.P.; Kahnberg, K.E.; Sundqvist, G. Survival of Arachnia propionica in periapical tissue. Int. Endod. J. 1988, 21, 277-282. [CrossRef] [PubMed]

43. Koppang, H.S.; Koppang, R.; Solheim, T.; Aarnes, H.; Stolen, S.O. Cellulose fibers from endodontic paper points as an etiological factor in postendodontic periapical granulomas and cysts. J. Endod. 1989, 15, 369-372. [CrossRef]

44. Yusuf, H. The significance of the presence of foreign material periapically as a cause of failure of root treatment. Oral Surg. Oral Med. Oral Pathol. 1982, 54, 566-574. [CrossRef]

45. Sedgley, C.M.; Messer, H. Long-term retention of a paper point in the periapical tissues: A case report. Endod. Dent. Traumatol. 1993, 9, 120-123. [CrossRef]

46. Nair, P.N.; Sjogren, U.; Schumacher, E.; Sundqvist, G. Radicular cyst affecting a root-filled human tooth: A long-term post-treatment follow-up. Int. Endod. J. 1993, 26, 225-233. [CrossRef]

47. Nair, P.N. New perspectives on radicular cysts: Do they heal? Int. Endod. J. 1998, 31, 155-160. [CrossRef]

48. Su, L.; Gao, Y.; Yu, C.; Wang, H.; Yu, Q. Surgical endodontic treatment of refractory periapical periodontitis with extraradicular biofilm. Oral Surg. Oral Med. Oral Pathol. Oral Radiol. Endod. 2010, 110, e40-e44. [CrossRef]

49. Ricucci, D.; Siqueira, J.F., Jr. Apical actinomycosis as a continuum of intraradicular and extraradicular infection: Case report and critical review on its involvement with treatment failure. J. Endod. 2008, 34, 1124-1129. [CrossRef]

50. Siqueira, J.F., Jr.; Rocas, I.N. Polymerase chain reaction detection of Propionibacterium propionicus and Actinomyces radicidentis in primary and persistent endodontic infections. Oral Surg. Oral Med. Oral Pathol. Oral Radiol. Endod. 2003, 96, 215-222. [CrossRef]

51. Zakaria, M.N.; Takeshita, T.; Shibata, Y.; Maeda, H.; Wada, N.; Akamine, A.; Yamashita, Y. Microbial community in persistent apical periodontitis: A $16 \mathrm{~S}$ rRNA gene clone library analysis. Int. Endod. J. 2015, 48, 717-728. [CrossRef] [PubMed]

52. Carlsson, J.; Frolander, F.; Sundquist, G. Oxygen tolerance of anaerobic bacteria isolated from necrotic dental pulps. Acta Odontol. Scand. 1977, 35, 139-145. [CrossRef] [PubMed]

53. Liet, S.; Sorin, S.M. Evaluation of clinical results based upon culturing root canals. J. Br. Endod. Soc. 1969, 3, 3-6. [CrossRef] [PubMed] 
54. Heling, B.; Shapira, J. Roentgenologic and clinical evaluation of endodontically treated teeth, with or without negative culture. Quintessence Int. Dent. Dig. 1978, 9, 79-84.

55. Hancock, H.H., 3rd; Sigurdsson, A.; Trope, M.; Moiseiwitsch, J. Bacteria isolated after unsuccessful endodontic treatment in a North American population. Oral Surg. Oral Med. Oral Pathol. Oral Radiol. Endod. 2001, 91, 579-586. [CrossRef] [PubMed]

56. Bowden, G.H.; Hamilton, I.R. Survival of oral bacteria. Crit. Rev. Oral Biol. Med. 1998, 9, 54-85. [CrossRef]

57. Hall, V.; Collins, M.D.; Hutson, R.A.; Inganas, E.; Falsen, E.; Duerden, B.I. Actinomyces oricola sp. nov., from a human dental abscess. Int. J. Syst. Evol. Microbiol. 2003, 53, 1515-1518. [CrossRef]

58. Yeguez, J.F.; Martinez, S.A.; Sands, L.R.; Hellinger, M.D. Pelvic actinomycosis presenting as malignant large bowel obstruction: A case report and a review of the literature. Am. Surg. 2000, 66, 85-90.

59. Acevedo, F.; Baudrand, R.; Letelier, L.M.; Gaete, P. Actinomycosis: A great pretender. Case reports of unusual presentations and a review of the literature. Int. J. Infect. Dis. 2008, 12, 358-362. [CrossRef]

60. Valour, F.; Senechal, A.; Dupieux, C.; Karsenty, J.; Lustig, S.; Breton, P.; Gleizal, A.; Boussel, L.; Laurent, F.; Braun, E.; et al. Actinomycosis: Etiology, clinical features, diagnosis, treatment, and management. Infect. Drug Resist. 2014, 7, 183-197. [CrossRef]

61. Sundqvist, G.; Reuterving, C.O. Isolation of Actinomyces israelii from periapical lesion. J. Endod. 1980, 6, 602-606. [CrossRef]

62. Moghimi, M.; Salentijn, E.; Debets-Ossenkop, Y.; Karagozoglu, K.H.; Forouzanfar, T. Treatment of cervicofacial actinomycosis: A report of 19 cases and review of literature. Med. Oral Patol. Oral Cir. Bucal. 2013, 18, e627-e632. [CrossRef] [PubMed]

63. Hirshberg, A.; Tsesis, I.; Metzger, Z.; Kaplan, I. Periapical actinomycosis: A clinicopathologic study. Oral Surg. Oral Med. Oral Pathol. Oral Radiol. Endod. 2003, 95, 614-620. [CrossRef] [PubMed]

64. Rubin, M.M.; Krost, B.S. Actinomycosis presenting as a midline palatal defect. J. Oral Maxillofac. Surg. 1995, 53, 701-703. [CrossRef]

65. Belmont, M.J.; Behar, P.M.; Wax, M.K. Atypical presentations of actinomycosis. Head. Neck. 1999, 21, $264-268$. [CrossRef]

(C) 2020 by the authors. Licensee MDPI, Basel, Switzerland. This article is an open access article distributed under the terms and conditions of the Creative Commons Attribution (CC BY) license (http://creativecommons.org/licenses/by/4.0/). 